\title{
INTERPRETACIÓN DE LA LEY EN LOS CÓDIGOS CIVILES: LITERALISMO SUDAMERICANO Y BLAGKSTONE
}

\author{
Gerardo Caffera ${ }^{1}$
}

\begin{abstract}
Resumen
William Blackstone, el renombrado jurista inglés del siglo dieciocho, influyó de manera directa sobre la redacción de las reglas de interpretación de la ley para el Código Civil de Luisiana, y de manera indirecta sobre las reglas para dicha materia en el Código Civil chileno (1855). Las reglas chilenas fueron tomadas subsiguientemente en Sudamérica por los redactores de los Códigos Civiles de Ecuador (1858), Venezuela (1862), Uruguay (1868) y Colombia (1887). Sostengo que la influencia de Blackstone fue significativa, y marcó diferencias con la tradición civil la cual, a su vez, determinó ciertas similitudes con el Literalismo del derecho inglés del siglo diecinueve. Sin embargo, el Literalismo sudamericano en la interpretación de la ley no fue una copia, sino una respuesta creativa a las realidades políticas locales. De la investigación sobre esta materia, los redactores de legislación sudamericanos aparecen como usuarios creativos y a la vez críticos, de ideas jurídicas fuentes que asombran por su variedad, incluyendo inesperadamente, unas de origen angloamericano. Es más, el contexto político sudamericano de mediados del siglo diecinueve sugiere que, en materia de argumentos del derecho comparado sobre la interpretación de la ley, hasta cierto punto, fueron utilizados de forma tan solo retórica.
\end{abstract}

Palabras clave: Interpretación de la ley, Códigos Civiles sudamericanos, Código Civil de Luisiana, Andrés Bello, William Blackstone.

\section{INTERPRETAGIÓN Y LAS LEYES}

\subsection{Una combinación creativa}

William Blackstone, un renombrado jurista inglés del siglo dieciocho, influyó de manera directa sobre la redacción de las reglas de interpretación de la ley para el Código Civil de Luisiana (1825), y de manera indirecta sobre las reglas para la

1 Universidad de la República, Montevideo, Uruguay; Universidad de Oxford, Oxford, Reino Unido (gerardo.caffera@law.ox.ac.uk). Traducción del inglés de Rodrigo Durán. 
misma materia en el Código Civil chileno (1855). Dichas reglas establecían que el significado literal debe prevalecer sobre la intención legislativa, y el "espíritu" de la ley. Las reglas chilenas fueron tomadas subsiguientemente en Sudamérica por los redactores de los Códigos Civiles del Ecuador (1858), Venezuela (1862), Uruguay (1868) y Colombia (1887). ${ }^{2}$

Sostengo que dicha influencia fue significativa, en atención a las marcadas diferencias a la tradición civil, y a las similitudes con el literalismo del derecho inglés. Asimismo, planteo que, en este asunto, Andrés Bello, el redactor del Código Civil chileno (1855) y Tristán Narvaja, el redactor del Código Civil uruguayo (1868), también utilizaron de forma directa y creativa las ideas de otro autor angloamericano, James Kent, también conocido como el Blackstone americano, con el fin de moderar algunas de las estrecheces del enfoque inglés.

No obstante, aún más interesante es la creatividad y la riqueza de las fuentes de inspiración que los redactores legislativos sudamericanos emplearon en el siglo diecinueve. Los recuentos históricos los presentan como devotos imitadores del Código Civil francés. ${ }^{3}$ Por ejemplo, López Medina ha indicado recientemente que

En los tradicionales y actuales mapas del derecho comparado (...) 'el derecho latinoamericano’ pasa a ser la estructura legal básica de las repúblicas ibéricas de las Américas que replican (...) el derecho posrevolucionario de Francia republicano. ${ }^{4}$

Sin embargo, una valoración realística, la cual ha sido apoyada por varios historiadores del derecho en las últimas décadas, demuestra que los redactores sudamericanos del siglo diecinueve de los Códigos Civiles eran usuarios tanto creativos como críticos de las ideas jurídicas provenientes de fuentes que asombran por su variedad. Sostengo que las ideas jurídicas angloamericanas deberían estar incluidas entre aquellas que fueron utilizadas de forma relevante por los redactores de los Códigos Civiles sudamericanos, tal como fue el caso del área de la interpretación de la ley, analizado en este artículo. Es más, y así como se explicará más adelante, el contexto político de Sudamérica de mediados del siglo diecinueve sugiere que, en materia de argumentos del derecho comparado sobre la interpretación de la ley, hasta cierto punto, fueron utilizados de forma tan solo retórica. Dejando de lado los detalles, el producto fue una combinación creativa la cual, se podría argumentar, sigue influenciando sobre las actitudes hacia la interpretación de la ley en Sudamérica.

\subsection{Modelos de Interpretación}

La interpretación de la ley es el proceso de discernir el significado de una ley para que se pueda aplicar. ${ }^{5}$ Cuando ocurrió la codificación del derecho privado en

2 Dichas reglas también salieron de Sudamérica, llegando a los Códigos Civiles de Nicaragua, Honduras y Panamá.

3 Ver, por ejemplo: Watson (1978), pp. 313-336.

4 López Medina (2012), p. 348.

5 Greenwalt (2002). 
Sudamérica, varios modelos estaban disponibles como fuentes de inspiración. ${ }^{6}$ Estos modelos se podían encontrar en normas jurídicas, o en las ideas de académicos jurídicos de las tradiciones civiles y de derecho común. Para los fines del presente artículo, se deben clarificar un conjunto de conceptos desde el inicio para permitir el análisis histórico y comparativo que sigue.

El primer punto es que, aun cuando la mayoría de los modelos de la interpretación de la ley reconocen que los jueces tienen un rol en la interpretación de la ley, en el pasado, otros modelos restringían esta tarea al soberano, o a la legislatura. Ejemplos de este último enfoque eran la máxima del ius commune "est enim eius interpretari cuius est concdere", ${ }^{7}$ o la institución francesa del référé au legislatif. ${ }^{8}$ Dichos modelos procuraban el asegurar el monopolio del soberano, o de la legislatura, como fuente única del derecho. En su versión moderna, el référé estaba vinculado con la doctrina de la separación de poderes postulado por Montesquieu. ${ }^{9}$ Su objetivo era el de evitar que los jueces ejercieran una función legislativa. Sin embargo, tal como notaron Blackstone y los redactores del Código Civil de Luisiana de 1825, a fin de cuentas, los référé le permitieron a la legislatura convertirse en juez, violando de esta manera el mismo principio de separación de poderes. ${ }^{10}$

Segundo, dentro de los modelos que admiten una interpretación judicial, se puede diferenciar de forma adicional entre aquellos modelos que incluyen detalladas reglas jurídicas que rigen el proceso de interpretación, y aquellos que prescinden de dichas reglas. El Código Civil de Luisiana (1825) fue un ejemplo del primero, mientras que el Código Civil francés (1804) fue un ejemplo del segundo.

Tercero, a grandes rasgos, se podían discernir dos métodos de interpretación para el momento en el que sucedió la codificación en Sudamérica: el método literal, el cual se basa en la regla literal ("plain meaning rule" del derecho anglosajón), y el método no literal que se basa en la intención de la legislatura, y la razón (espíritu) de la ley. La interpretación literal se enfoca en el significado de las palabras tomadas aisladamente o según su contexto. Prescribe distintas formas de adjudicarle significado dependiendo del tipo de lenguaje que utilice la legislatura. Por otro lado, la interpretación no literal se enfoca en el espiritu o la razón de la ley, o en la intención de la legislatura. En lugar de una exégesis textual, los jueces deben contemplar con cuidado los "fundamentos subyacentes de los textos y de las prácticas"."

Finalmente, entre aquellos modelos que prescriben reglas con el propósito de regir la interpretación judicial, se puede hacer una distinción adicional entre los modelos jerárquicos y no-jerárquicos. Tal como ha notado Greenawalt, uno de los temas

6 Se puede encontrar una excelente revisión de este tema en GuZMán BRITO (2011).

7 Pluaknett (2010), p. 329.

8 Van Caenegem (1992), p. 130.

9 Van Caenegem (1992), p. 130.

10 Ver sección 2.3 siguiente.

11 Greenwalt (2002), p. 269. 
mayormente discutidos en la interpretación de la ley es el papel que deberían desempeñar respectivamente las "ideas del legislador sobre lo que han promulgado y la comprensión del lector de dichas promulgaciones". ${ }^{12}$ En otras palabras, tal como ha dicho Manning, "el asunto de texto versus propósito siempre ha presentado problemas para el derecho de la interpretación de las leyes" ${ }^{13}$ Los modelos jerárquicos privilegian el método literal de interpretación por sobre otros. Por el contrario, los modelos no-jerárquicos permiten la utilización alternativa o simultánea del texto, la intención de la legislatura, y la razón (espiritu) de la ley. Tanto el Código Civil de Luisiana (1825) como los escritos de Blackstone, fueron ejemplos de modelos jerárquicos en los que se priorizó el método literal, y recurrir a la intención de la legislatura se permitía solamente si no quedaba claro el significado literal. Este enfoque era típico de los actores del derecho que estaban "preocupados con restringir la discreción judicial". ${ }^{14}$ Por el contrario, el académico francés Jean Domat, sugirió un modelo dentro del cual se podrían utilizar los métodos literales y no-literales de manera simultánea. ${ }^{15}$

Es menester hacer algunas observaciones metodológicas adicionales. Primero, el análisis histórico y comparativo que se realizará en las siguientes secciones se desarrollará en base a las ideas simplificadas sobre la interpretación de la ley, que se presentaron anteriormente. Por supuesto, los asuntos son más complejos de lo que tienden a sugerir aquellas ideas. Por ejemplo, la regla del significado sencillo o literal establece que, si el texto de la ley es claro, no debe ser desestimado, y que la intención de la legislatura debe ser tomado en consideración solamente si el texto no es claro. Sin embargo, Ronald Dworkin, por ejemplo, ha sostenido que el describir un texto legal como "no claro" es el resultado inevitable de considerar la razón o el propósito de la ley, y no la ocasión de contemplar dicha razón ${ }^{16}$. De manera similar, la "intención" de la legislatura también resulta ser un concepto problemático. Algunos juristas, como Jeremy Waldron, niegan la existencia de dicha intención, por lo menos en el caso de asambleas con múltiples miembros, como los parlamentos modernos. ${ }^{17}$

Segundo, un problema adicional versa sobre la clara influencia que han tenido sobre las opiniones de autores en particular, las ideas más generales sobre la teoría jurídica. Por ejemplo, Jean Domat y Samuel Pufendorf, dos autores que son frecuentemente consultados en Europa y en América respecto del tema de la interpretación de la ley, pertenecían a la escuela del derecho natural. Esto influyó en sus ideas sobre la interpretación de la ley, particularmente su sugerencia de que aún el significado

12 Greenwalt (2002), p. 277.

13 Manning (2001), p. 4.

14 Greenwalt (2002), p. 289.

15 Domat (1737), p. 7.

16 DWORKIn (1998), p. 352.

17 WaLdron (1999), pp. 121 y 142. De forma reveladora, el Código chileno dirigía al juez a que buscara la intención de la legislatura primeramente dentro del texto de la ley misma. Esto podría ser muestra de la percepción de Bello de la naturaleza problemática del concepto de intención legislativa, y no solamente sobre la falta de fuentes confiables de conocimiento sobre dicha intención. 
claro y literal de la ley se debe desestimar en caso de que sea injusto. Las ideas de Blackstone sobre la interpretación de la ley conllevan sus propios problemas. Particularmente, aun cuando la concepción general de Blackstone sobre el derecho se inclinaba más hacia el lado de la doctrina del derecho natural (él argumentó célebremente que una mala ley no es ley), su enfoque de la interpretación de la ley parecía estar más alineado con el pensamiento positivista. En su opinión, sin importar lo poco razonable que fuese una ley, esta podría ser desestimada por el juez. Por tanto, Hart sostenía que la prueba del derecho natural de Blackstone para el derecho positivo era vacía, y que cualquier ley positiva la podría $\operatorname{pasar},{ }^{18}$ y Gareth Jones sostuvo que parecía ser imposible reconciliar las ideas de Blackstone sobre el derecho natural con su concepción del soberano "descontrolado". ${ }^{19}$

Tercero, las posturas de diversos juristas que se analizan en el presente artículo no eran tan definidas como podrían sugerir las secciones que se encuentran a continuación. Todas sus obras hacían referencia a un conjunto común de temas y máximas (varias de ellas provenientes del derecho romano). A primera (e incluso segunda) vista, pareciera que estos estudiosos proporcionan un arsenal similar y levemente incoherente, de máximas y de principios. Con la finalidad de identificar la diferencia entre ellas, es importante ver el panorama completo de sus ideas, y no enfocarse demasiado en los detalles aislados de sus concepciones respectivas de la interpretación de la ley. Blackstone es un claro ejemplo de la ambigüedad anteriormente señalada. Mientras que en su análisis del derecho escrito inglés Blackstone pareciera inclinarse más a otorgarle a los jueces algo de discreción (ej. bajo la "Regla de Malicia"), ${ }^{20}$ en sus explicaciones generales del tema de la interpretación de la ley (aquella que influyó en el Código Civil de Luisiana), adoptó una postura mucho más formalista, y advirtió a sus lectores en contra de la discreción en la interpretación.

\subsection{Historia intelectual: aproximaciones internalistas vs. contextualistas}

Aun cuando las ideas sobre la naturaleza de la interpretación de la ley son siempre complejas, en mi opinión son lo suficientemente claras para los fines de la tarea histórica y comparativa que constituye la base del presente artículo. Podemos lidiar con ideas pasadas en dos formas distintas: mediante una crítica interna de dichas ideas, o mediante el análisis de lo que estaban haciendo con ellas dentro de su contexto histórico. Por ende, dos metodologías distintas han sido propuestas dentro del campo de la historia de las ideas. Algunos académicos, como Peter Strawson, han sido descritos como haber "liberado la historia de la filosofía de la historia", ${ }^{21}$ para el propósito de enfocarse en las fortalezas internas y en las debilidades de las ideas concebidas como estrategias para la resolución de problemas. Por el contrario,

18 HART (1956).

19 Jones (1973), p. xxxviii.

20 Según lo cual el juez, al interpretar una ley, debe considerar no solamente su texto, sino también la 'malicia' del common law que dicha ley buscaba resolver.

21 Para este párrafo: Jones (1973), pp. 508-11 
Quentin Skinner y otros historiadores han enfatizado la importancia de una comprensión histórica de las ideas por sobre la crítica filosófica interna. De acuerdo a Skinner, necesitamos estudiar el contexto de cualquier obra de filosofía política con tal de permitirnos "caracterizar lo que estaban haciendo sus autores al escribirlas". ${ }^{22}$

Richard Rorty ha representado acertadamente la contraposición. Por un lado, dice él, los "filósofos tradicionales normalmente consideran su disciplina como aquella que versa sobre problemas perennales y eternos", ${ }^{23}$ mientras que, por otro lado, Wittgenstein y otros han elaborado un mensaje "historicista", contemplando la visión tradicional como un mero "intento de eternalizar un cierto juego de lenguaje contemporáneo, o una práctica social o auto-imagen". ${ }^{24}$ Esto no es desconocido para la academia jurídica: una contraposición similar se puede encontrar en la teoría legal del debate entre el formalismo ${ }^{25}$ y el realismo de los escépticos de reglas. ${ }^{26}$ En otras palabras, la pregunta siempre será si deberíamos analizar la coherencia interna de las ideas jurídicas, como lo instan los formalistas, o si deberíamos adoptar una posición y un enfoque realista en lo que los actores del derecho en realidad estaban haciendo con aquellas ideas. Entre los historiadores del derecho, pocos habrían desafiado la noción de que su tarea es el comprender ideas jurídicas dentro de su contexto histórico. ${ }^{27}$ Sin embargo, no existe inconveniencia en tener un enfoque ahistórico, siempre que dicho enfoque no se presente como un enfoque histórico. ${ }^{28}$

Volviendo a nuestro tema: podemos considerar que los literalistas eran completamente ingenuos al sugerir que los jueces nunca deberían desestimar los textos claros, y podríamos mirar con escepticismo cualquier mención del intento de la legislatura para hacerlo. Sin embargo, dichas ideas aún continúan con un significado central clave, con el resultado de que sigue siendo posible el comprender lo que los juristas y los redactores estaban haciendo (o intentando hacer) con las mismas dentro del contexto de las problemáticas sudamericanas. En verdad, el vocabulario del literalismo, intención legislativa, interpretación con propósito, etc., sigue siendo ampliamente utilizado en la teoría del derecho, demostrando que dicho lenguaje es capaz de comunicar una idea razonablemente clara de lo que se está haciendo con dichas ideas en medio de los debates políticos.

\footnotetext{
22 Skinner (1978), p. xiii.

23 RorTy (1979), p. 3.

24 RorTy (1979), pp. 9-10. Énfasis añadido.

25 Por ejemplo: WeInRIB (2012), pp. 22-55

26 Por ejemplo: Frank (1949), pp. vii.-xiv. Según Frank, los realistas escépticos de las reglas intentan revelar las "reglas verdaderas" usadas por los jueces en vez de las "reglas de papel" invocadas por ellos.

27 Lobban (2004), p. 3.

28 Lobban (2004), p. 12.
} 


\subsection{Blackstone y Sudamérica: el rastro y sus incertidumbres}

Tal como se mencionó anteriormente, el Código Civil chileno (1855) fue inspirado indirectamente por los Comentarios de Blackstone, mediante el vehículo del Código Civil de Luisiana (1825), y, en Sudamérica, las reglas del Código Civil Chileno fueron tomadas por los Códigos Civiles del Ecuador, Venezuela, Uruguay y Colombia. En mi opinión, el uso de Blackstone fue importante porque marcó la diferencia con la tradición del derecho civil.

Sin embargo, dicha posición debe enfrentar ciertos problemas. Aun cuando es claro que el lenguaje de las reglas de interpretación de la ley del Código de Luisiana fue tomado directamente de Blackstone, Blackstone mismo fue inspirado por algunos autores civiles (notablemente por Samuel Pufendorf), y, por ende, algunas de sus ideas tenían en realidad un origen civil. Basándose en lo anterior, Guzmán Brito ${ }^{29}$ ha sostenido que Blackstone era solamente un intermediario entre la tradición civil y los redactores del Código Civil de Luisiana. Lo anterior implicaría que el rol que tuvo Blackstone no era significativo. Además, los apuntes del redactor sobre las reglas de interpretación de la ley contenidos en el Código Civil de Luisiana, Louis Moreau Lislet, ${ }^{30}$ no hacían mención de Blackstone, sino que de Jean Domat (otro autor civilista prominente), y al derecho español. ${ }^{31}$ Aun cuando los apuntes de Moreau Lislet son muchas veces engañosos, ya que frecuentemente se refieren a ideas distintas o contradictorias, y se enfocan solamente en el derecho español y romano, ${ }^{32}$ este aspecto aún debe ser considerado. Finalmente, por lo menos un artículo del Código Civil de Luisiana fue inspirado por el jamás promulgado borrador del Código Civil francés del Año VIII de la Revolución (1800). Todos los puntos anteriormente señalados muestran la necesidad de explorar si estos candidatos alternativos fueron las fuentes genuinas de inspiración para el Código Civil de Luisiana, aun si las palabras empleadas de los artículos del Código de Luisiana fueron tomadas de Blackstone.

Independiente de las explicaciones alternativas que se han sugerido, sostengo que la influencia de Blackstone fue la influencia dominante, y que el Código Civil de Luisiana marcó un cambio de los modelos civilistas de dicha época. Al establecer la prevalencia de la regla literal, al rechazar el référé au legislatif, y al intentar limitar la discreción judicial mediante reglas detalladas de interpretación, el Código Civil de Luisiana tomó prestado de Blackstone. Es más, al inicio del siglo diecinueve, las ideas de Blackstone fueron considerados por el académico estadounidense James Kent para representar la visión dominante de la época del derecho inglés. De acuerdo a dichas ideas, "un acto de un Parlamento entregado en términos claros e inteligibles,

29 GuZMÁn Brito (2009).

30 Moreau Lislet (1968).

31 Según Cairns, otra copia del compendio de Luisiana de 1808, conocida como el manuscrito Mouton, con anotaciones hechas por a lo menos dos abogados de Luisiana, mencionaba a Blackstone en relación con seis disposiciones. Sin embargo, esto no ocurrió en conexión con la interpretación de la ley. Cfr. Cairns (2009), p. 72.

32 Cairns (2009), p. 78-9. 
no podrá ser cuestionado (...) en ninguna corte de justicia” ya que el Parlamento era "la autoridad máxima reconocida por el reino sobre la tierra". ${ }^{33}$ Las ideas de Blackstone fueron contrastadas por Kent de aquellas de Sir Edward Coke, quien, para los inicios del siglo diecisiete, había sostenido de manera célebre que "en muchos casos el derecho común controlará los actos del Parlamento". ${ }^{34}$ Por medio de Blackstone, el Código de Luisiana, y otros códigos sudamericanos subsiguientes, llegaron a compartir una característica notoria del derecho inglés: la supremacía en la interpretación de la ley del significado sencillo o la regla literal. Por supuesto, también existían otras similitudes con fuentes civiles, tal como demostraré, pero dichas potenciales fuentes alternativas de inspiración no proporcionan un modelo de la interpretación de la ley similar a la de Blackstone o al inglés.

\subsection{Plan de las secciones subsiguientes}

En las siguientes secciones, mostraré las influencias relevantes con la finalidad de sustentar mis tesis. Primero, analizaré el Louisiana Digest (1808), el Código Civil de Luisiana de 1825, y el rol que tuvieron las ideas Blackstoneanas inspirando sus reglas de interpretación de la ley. En segundo lugar, exploraré y relativizaré el impacto de las posibles fuentes alternativas de inspiración para el Código Civil de Luisiana. La finalidad será la de demostrar que las ideas de Blackstone proporcionaron una inspiración dominante, y que el redactor del Código de Luisiana no siguió de forma estricta la tradición civilista. En tercer lugar, analizaré las reglas del Código Civil Chileno sobre la interpretación de la ley que fueron inspirados por el Código Civil de Luisiana (1825), con la intención de demostrar que el uso indirecto de las ideas de Blackstone marcaron un alejamiento de la tradición civil, conduciendo a cierta convergencia fáctica con el derecho inglés del siglo diecinueve. La influencia de las reglas del Código Civil Chileno sobre el Código Civil de Uruguay (1868) también se presentarán, para los fines de demostrar el uso de los escritos de James Kent como fuente adicional de inspiración. Cuarto, exploraré brevemente si Bello estaba consciente o no de estar utilizando ideas angloamericanas en el tema de la interpretación de la ley, y en caso de que se sostenga una respuesta afirmativa, porqué él no reconoció dicha utilización. Finalmente, se presentarán algunas conclusiones generales.

\section{BLAGKSTONE Y EL GÓDIGO GIVIL DE LUISIANA}

\subsection{La Influencia}

Antes de ser incorporado a los Estados Unidos en 1803, Luisiana fue colonia de Francia, de España, y de Francia de nuevo, sucesivamente. Así, siempre había pertenecido a la tradición del derecho civil. Su ingreso a los Estados Unidos pre-

33 Kent (1854), p. 493.

34 Dr. Bonham's Case, 8 Co. Rep. 114 (1610). 
sentó un dilema para las clases gobernantes de Luisiana entre el permanecer en la tradición del derecho civil, y ser absorbido por el mundo del derecho común. Con el objetivo de evitar lo segundo, en 1806 la legislatura aprobó un acto declarando que el derecho romano y español regía en Luisiana, pero fue vetado por el gobernador angloamericano. ${ }^{35}$ Sin embargo, poco tiempo después, el Compendio de Luisiana de 1808, redactado por Louis Moreau Lislet y James Brown, e inspirado principalmente por el derecho francés y español, fue promulgado. ${ }^{36} \mathrm{El}$ Compendio de 1808 incluía un número de reglas sobre la interpretación de la ley. En 1825, se promulgó un nuevo Código Civil, el cual retenía las mismas reglas sobre la interpretación de la ley. Así, en las páginas siguientes me referiré de forma indiscriminada entre las reglas sobre interpretación del Compendio (1808) y del Código Civil de Luisiana (1825) como el mismo conjunto de reglas.

Las reglas del Compendio de Luisiana (1808) y del Código Civil (1825) tenían dos fuentes principales: referente al artículo 13, el borrador francés del Código Civil del Año VIII (en adelante el "Proyecto Francés"), ${ }^{37}$ y referente a los artículos 14 al 18, los Comentarios de Blackstone. Se ha dicho que los escritos de Blackstone son "una sorprendente presencia (...) en un Código Civil, particularmente para asuntos de interpretación de la ley, lo cual ha sido discutido extensivamente por Domat". ${ }^{38}$ Sin embargo, este no era el único aspecto por el cual sirvieron como inspiración los escritos de Blackstone, ya que su influencia se ha encontrado en relación a otros diecinueve artículos del Código Civil de Luisiana. ${ }^{39}$

De acuerdo a Rodolfo Batiza, un importante jurista estudioso de Luisiana, los artículos 14 al 18 del Código Civil de Luisiana fueron una transcripción palabra-por-palabra, o casi palabra-por-palabra, de Blackstone. ${ }^{40}$ Este hecho ha sido aceptado por Antonio Bascuñán ${ }^{41}$ y por Alejandro Guzmán Brito en Chile.42 La siguiente tabla proporciona textos del Código de Luisiana y sus fuentes correspondientes de inspiración, de acuerdo a Batiza y a Guzmán Brito:

35 FrankLin (1941 -1942).

36 Barham (1975 - 1976); Herman (2008), pp. 2-6.

37 Commission Nommée par le Gouvernement le 24 Thermidor An VIII, Projet de Code Civil (Chez Emery Ventóse an IX-1801).

38 Batiza (1971), p. 29.

39 Tucker (1969-1970). Batiza (1971), p. 12.

40 Batiza (1971), p. 29.

41 Bascuñán Rodríguez (2014), p. 306.

42 Según Guzmán Brito (2009) 


\begin{tabular}{|c|c|}
\hline Fuente de Inspiración ${ }^{43}$ & $\begin{array}{l}\text { Código Civil de Luisiana (idénticas a las } \\
\text { disposiciones del Compendio de 1808) }\end{array}$ \\
\hline $\begin{array}{l}\text { Artículo V del Proyecto Francés Año } \\
\text { VIII: Cuando la ley sea clara, su letra } \\
\text { no debe ser eludida bajo el pretexto } \\
\text { de buscar su espíritu, y en la aplica- } \\
\text { ción de una ley obscura, se debe pre- } \\
\text { ferir su sentido más natural y menos } \\
\text { defectuosa. }\end{array}$ & $\begin{array}{l}\text { Art. 13. Cuando una ley es clara y libre de toda } \\
\text { ambigüedad, la letra de la misma no se debe deses- } \\
\text { timar, bajo el pretexto de estar buscando el espíritu } \\
\text { de la misma. }\end{array}$ \\
\hline $\begin{array}{l}\text { Blackstone: Generalmente, las pala- } \\
\text { bras se deben comprender según su } \\
\text { significado usual y más conocido; no } \\
\text { tanto así en cuanto a la propiedad de } \\
\text { la gramática, sino en cuanto a su uso } \\
\text { general y popular. }\end{array}$ & $\begin{array}{l}\text { Art. 14. Generalmente las palabras de una ley se } \\
\text { deben entender según su significado más conoci- } \\
\text { do y usual, sin atender tanto a las sutilezas de las } \\
\text { reglas gramaticales, como al uso general y popular } \\
\text { de los términos. }\end{array}$ \\
\hline $\begin{array}{l}\text { Blackstone: ... los términos de las } \\
\text { artes, o términos técnicos, deben ser } \\
\text { considerados según la acepción de los } \\
\text { doctos en cada arte, oficio y ciencia. }\end{array}$ & $\begin{array}{l}\text { Art. } 15 \text {. Los términos de las artes, o términos téc- } \\
\text { nicos y frases, se deben interpretar según el signifi- } \\
\text { cado recibido y la acepción de entre los doctos en } \\
\text { el arte, el oficio, o la profesión a los que se refieren. }\end{array}$ \\
\hline $\begin{array}{l}\text { Blackstone: Si las palabras continúan } \\
\text { siendo ambiguas, podemos estable- } \\
\text { cer su significado del contexto; con } \\
\text { lo cual, puede ser de utilidad compa- } \\
\text { rarla con una palabra, o con una ora- } \\
\text { ción, cuando sean ambiguas, equívo- } \\
\text { cas o complejas. }\end{array}$ & $\begin{array}{l}\text { Art. 16. Cuando las palabras de una ley sean ambi- } \\
\text { guas, su significado podrá ser buscado examinando } \\
\text { el contexto con el cual se pueda comparar la pala- } \\
\text { bra, frase u oración ambigua, con la finalidad de } \\
\text { establecer su significado real. }\end{array}$ \\
\hline $\begin{array}{l}\text { Blackstone: (texto introducido por el } \\
\text { director de la decimoprimera edición } \\
\text { de los Comentarios de Blackstone): ... } \\
\text { leyes que versen sobre pari materia, o } \\
\text { sobre el mismo tema, deben ser in- } \\
\text { terpretadas haciendo referencia entre } \\
\text { ellas; es decir, lo que es claro en una } \\
\text { ley, debe ser tomado a modo de auxi- } \\
\text { liar para explicar lo que es obscuro y } \\
\text { ambiguo en la otra. }\end{array}$ & $\begin{array}{l}\text { Art. 17. Leyes pari materia, o que versen sobre el } \\
\text { mismo tema, deben ser interpretadas haciendo re- } \\
\text { ferencia entre ellas; lo que es claro en una ley pue- } \\
\text { de ser tomado a modo de auxiliar la explicación de } \\
\text { lo que es dudoso en la otra. }\end{array}$ \\
\hline $\begin{array}{l}\text { Blackstone: la forma más universal y } \\
\text { efectiva de descubrir el verdadero sig- } \\
\text { nificado de una ley, cuando las pala- } \\
\text { bras son ambiguas, es considerando la } \\
\text { razón y el espíritu de ella, que inspiró } \\
\text { a la legislatura para promulgarla. }\end{array}$ & $\begin{array}{l}\text { Art. 18. La forma más universal y efectiva de des- } \\
\text { cubrir el verdadero significado de una ley, cuando } \\
\text { sus expresiones sean ambiguas, es considerando la } \\
\text { razón y el espíritu de ella, o la causa que indujo a } \\
\text { la legislatura para promulgarla. }\end{array}$ \\
\hline
\end{tabular}

43 Guzmán Brito (2009). 
Tal como demuestra esta tabla, formalmente, la mayoría de las reglas del Código de Luisiana siguen de manera muy cercana las palabras empleadas por Blackstone. Sustancialmente, aquellas reglas adoptaron un modelo jerárquico de interpretación, en el cual se le daba prioridad al método literal. De acuerdo al Código, se permitía recurrir al espíritu de la ley y a la intención del legislador solamente cuando "las expresiones se presentaban como ambiguas". ${ }^{44}$ Más aun, un conjunto de reglas guiaba al juez. Dichas reglas sobre la interpretación fueron redactas por Louis Moreau Lislet, ${ }^{45}$ un abogado civilista y un émigré francés ${ }^{46}$ quien estaba familiarizado con los autores civilistas y del common law en general ${ }^{47}$. Su biblioteca incluía una copia de los Comentarios de Blackstone ${ }^{48}$ y en un informe presentado a la legislatura de Luisiana, él junto con otros dos redactores del Código de 1825, reconocieron haber recurrido a "las abundantes fuentes de Jurisprudencia inglesa". ${ }^{49}$

En las siguientes secciones plantearé que Blackstone pre-figuraba las características principales del derecho inglés del siglo diecinueve sobre la construcción de la ley, ${ }^{50}$ y que el Código Civil de Luisiana seguía de forma bastante estricta, no solamente la redacción, sino también las ideas de Blackstone en la interpretación de la ley.51

\subsection{Blackstone y el derecho inglés respecto de la interpretación de la ley}

El desarrollo de la interpretación del derecho inglés se ha dividido en tres períodos: equidad de la ley (equity of the statute, hasta 1830), el literalismo estricto (de 1830 a 1950), y la interpretación teleológica (de 1950 hasta el presente). ${ }^{52}$ El desarrollo del literalismo, de acuerdo a Plucknett, se remonta a la mitad del siglo catorce. ${ }^{53}$ En aquella época, las leyes eran "consideradas como textos que deben ser aplicados tal y como se establecen". ${ }^{54}$ Formalmente privados de cualquier poder discrecional, los jueces del common law "se refugiaban en la lógica" y establecían reglas de interpretación de la ley de "gran complejidad". De acuerdo a Plucknett, Blackstone y Kent, en sus Comentarios, proporcionaron un bosquejo razonable de un sistema elaborado por los tribunales del common law. ${ }^{55}$ Sin embargo, el método de interpretación basado en el equity of the statute, aceptado en el derecho inglés hasta el siglo dieciocho, le

\footnotetext{
44 Artículo 18 del Código Civil de Luisiana.

45 Batiza (1971), p. 28.

46 PARISE (2012).

47 Batiza (1971), p. 28

48 Franklin (1940-1941), p. 405.

49 Livingston et. al. (1823), p. 6.

50 Sección 2.2. siguiente.

51 Sección 2.3. siguiente.

52 LÜCKE (2005).

53 Plucknett (2010), p. 333

54 Plucknett (2010), p. 333

55 Plucknett (2010), p. 334, nota al pie 1.
} 
proporcionaba un margen de discreción al juez para evitar "resultados injustos". ${ }^{56}$ De acuerdo a Bromley C.J., quien escribió en 1554, dicho método les permitía a los jueces exponer "las palabras muy contrarias al texto (de la ley) con tal de que calcen con la razón y la equidad". ${ }^{57}$ Era el equivalente del método de interpretación de la tradición del derecho civil, el cual se basa en la razón o en el espíritu de la ley.

El vuelco a un planteamiento estrictamente literalista ocurrió en el siglo diecinueve, y se representó acertadamente por la decisión de la Cámara de los Lores en el Sussex Peerage Claim de 1844: "si las palabras de los estatutos son en sí precisos y faltos de ambigüedad, entonces nada más que exponer dichas palabras puede ser necesario...". ${ }^{58}$ Esta regla es conocida en el derecho inglés como la regla literal o de significado sencillo (plain meaning). ${ }^{59}$ La tradición judicial inglesa de restringir la interpretación al 'significado llano' de la ley persistió hasta muy recientemente. ${ }^{60}$ Para la mayor parte del siglo veinte, las cortes británicas rehusaban analizar la intención de la legislatura. ${ }^{61}$ Waldron notó que la "referencia hecha a la intención legislativa es $(\ldots)$ menos común en Inglaterra (que en América)". ${ }^{62}$ Es más, los jueces ingleses solamente recurrían al contexto de las palabras cuando no era claro el significado común. ${ }^{63}$

Finalmente, la reticencia de los jueces ingleses del siglo diecinueve a buscar la intención de la legislatura era una piedra angular para el derecho inglés hasta muy recientemente. Originalmente, en un caso de $1769,{ }^{64}$ la desconfianza en el indagar en la intención de la legislatura parecer haberse basado en la falta de materiales confiables ${ }^{65}$ pero en los años 70, cuando los Informes Hansard pasaron a ser materiales claramente confiables, aún seguían siendo criticados por otra razón: muchas veces contenían declaraciones contradictorias durante los debates parlamentarios, y respuestas no bien consideradas. ${ }^{66}$

La contraposición entre el derecho inglés y el derecho civil sobre la interpretación de la ley muchas veces se resume como una entre el textualismo y el intencionalismo:

[E]l enfoque inglés se basa principalmente en determinar el significado llano de las palabras usadas, mientras que, en el derecho civil, se busca determinar la intención de la legislatura. ${ }^{67}$

\footnotetext{
56 Manning (2001), p. 8

57 Fulmerston v. Steward (1554).

58 Sussex Peerage Case (1844), p. 43.

59 Harris (2007), p. 157.

60 Bix (2015), p. 165. Bix cita a Pepper v. Hart (1993)

61 Greenwalt (2002)

62 Waldron (1999), p. 119.

63 EndicotT (2002), p. 949.

64 Millar v. Taylor (1769), p. 2332 (Willes J.)

65 Vogenauer (2005), p. 631.

66 Vogenauer (2005), p. 630.

67 Freeman (2008), p. 1555.
} 
Blackstone prefiguraba todas las ideas centrales del estricto literalismo inglés. ${ }^{68}$ Sus escritos sistematizaban las reglas desarrolladas en las cortes de common law y al hacerlo, tal como él lo hacía frecuentemente, Blackstone también tomó inspiración de la tradición del derecho civil. En este caso, él se apoyaba mucho en las obras de Samuel Pufendorf. Las ideas principales de Blackstone se pueden explicar de la siguiente manera: primero, Blackstone rechazaba el método de interpretación por la legislatura (référé au legislatif), ya que él consideraba que permitía "mucho espacio para la parcialidad y para la opresión". ${ }^{69}$

En segundo lugar, él apoyaba un método jerárquico de interpretación, el cual se componía de tres niveles. En la primera instancia, existía una regla literal, la cual consistía en interpretar el significado de las palabras tomadas en su "significado usual y más conocido", o en el caso de "los términos de arte, o términos técnicos", su significado "en cada arte, oficio y ciencia". Esta regla solo admitía excepciones cuando las palabras relevantes carecían de sentido o en caso de tener un sentido absurdo (la llamada regla de oro), ${ }^{70}$ por ejemplo, debido a la existencia de una contradicción lógica. La "regla de oro" no se podía aplicar solamente porque el juez estimaba que cierto significado era poco razonable o injusto. ${ }^{71}$ En el segundo nivel, Blackstone recomendaba el recurrir al contexto de la ley solamente si las palabras relevantes "parecían aún ser ambiguas". Por contexto, Blackstone entendía el preámbulo de una ley y "otras leyes (...) que tienen alguna relación con la materia".72 Hacer referencia al contexto solamente en casos de duda, sería otra característica central del derecho inglés en esta materia. En verdad, el enfoque "sin-contexto" se relajó solamente después del caso Príncipe de Hanover en 1957, ${ }^{73}$ en la que la Cámara de los Lores sostuvo que el contexto se debe considerar aún en casos en los que era claro el significado de las palabras. ${ }^{74}$ Finalmente, en un tercer nivel, Blackstone indicaba que, si "las palabras continúan siendo ambiguas", se podría recurrir a la razón de la ley (su espíritu) o "a la causa que impulsó al legislador a promulgarla" (la intención de la legislatura). ${ }^{75}$ La preferencia que tenía Blackstone para la regla literal o de significado llano se ilustra mediante su visión de que la razón de la ley se debería examinar solamente si eran ambiguas las palabras relevantes. Marcando su discrepancia con otros actores legales (no-identificados) de su época, Blackstone comunica

68 Según Manning (2001), la doctrina de equidad de la ley fue abandonada de forma progresiva después que el principio de separación de poderes triunfó en la revolución inglesa de 1688, y el literalismo comenzó a surgir durante el siglo dieciocho. Los escritos de Blackstone se deben mirar desde este contexto.

69 Blackstone (1783), p. 59.

70 Harris (2007), p. 158.

71 Tal como señala Harris "tanto la regla literal como la regla de oro enfatizan la fidelidad a las palabras del legislador, aunque el segundo admite considerar las consecuencias". HarRIS (2007), p. 158.

72 Blackstone (1783), p. 60.

73 Attorney-General v. Prince Ernest Augustus of Hanover (1957).

74 EndicotT (2002), p. 949.

75 Blackstone (1783), p. 60. 
claramente su opinión que la letra de la ley se debe seguir, aun cuando le parezca poco razonable al juez"

\begin{abstract}
Sé que se establece generalmente (...) que los actos parlamentarios contrarios a la razón son nulos. Pero si el Parlamento promulgará de forma positiva algo que se debe hacer que no sea razonable, no conozco poder alguno en la forma ordinaria de la Constitución que esté investido con autoridad para controlarlo. ${ }^{76}$
\end{abstract}

Según la perspectiva de Blackstone, el hacer que esté disponible para el poder judicial la posibilidad de declarar leyes no-razonables como nulas "sería subversivo para todos los gobiernos". ${ }^{77}$ Desconfiaba de igual manera de la doctrina de la equidad de la ley: "el cual convertiría a cada juez en un legislador, e introduciría una confusión infinita". ${ }^{78}$ Aun cuando Blackstone tenía una tendencia hacia doctrinas del derecho natural, y argumentaba a favor de la propuesta que una ley mala no es ley alguna, él suscribía claramente a un enfoque literal a la interpretación de la ley, la cual parece ser contraria a las enseñanzas de la escuela del derecho natural.

Así, las ideas de Blackstone eran muy similares a aquellas que dominarían el derecho inglés durante el siglo diecinueve cuando "la fidelidad a la palabra escrita (de las leyes) se encontraba en su cúspide". ${ }^{79}$ Tal como se ha mencionado, ${ }^{80}$ Kent consideraba que Blackstone era un representante visible de la marcada preferencia inglesa del derecho nacido en el Parlamento.

\title{
2.3. Coincidencias entre Blackstone y el Código de Luisiana
}

El Código Civil de Luisiana no utiliza solamente frases de los Comentarios de Blackstone, sino que encarnan las ideas sustantivas de Blackstone sobre la interpretación de la ley. Primeramente, manteniendo la línea con Blackstone, el Código Civil de Luisiana no adoptó el mecanismo de référé au legislatif. En segundo lugar, al método literal de interpretación se le otorgó prioridad estricta en virtud del Artículo 13, mientras que la intención de la legislatura y la razón de la ley solamente debían ser consideradas en caso de que fuese "ambiguo" el significado de la letra (Artículo 18 del Código Civil de Luisiana) ${ }^{81}$ La redacción de la regla era idéntica a la de los Comentarios de Blackstone. Así, tal como gran parte del material de Blackstone, el Código Civil de Luisiana adoptó un modelo jerárquico de la interpretación de la ley. Tercero, de acuerdo al Código Civil de Luisiana, el contexto de las palabras se debía

\footnotetext{
76 Blackstone (1783), p. 91.

77 Blackstone (1783), p. 91.

78 Blackstone (1783), p. 62.

79 Harris (2007), p. 159.

80 Sección 1.4 anterior.

81 Ver sección 2.1 anterior.
} 
considerar solamente si los significados de dichas palabras eran "ambiguas" (artículo 16 del Código Civil de Luisiana). Blackstone sostenía lo mismo: "si las palabras siguen siendo ambiguas, podemos establecer su significado en base al contexto". ${ }^{82}$ Finalmente, el Código Civil de Luisiana incluía, en sus artículos 14 y 15, las mismas reglas detalladas establecidas por Blackstone con el fin de guiar al juez en la actividad de la interpretación: las palabras se debían interpretar de acuerdo a su significado común, salvo que aparezca que se utilizaron en un sentido técnico, en cuyo caso debe prevalecer su significado técnico. ${ }^{83}$

Las disposiciones del Código no solo indicaron las coincidencias entre las opiniones de los redactores del Código Civil de Luisiana y Blackstone. En un informe de $1823,{ }^{84}$ dichos redactores dijeron explícitamente que el référé involucraba la "manifiesta injusticia de crear derecho con referencia a un caso existente", y, por ende, la unión de los poderes judiciales y legislativos, lo cual estaba prohibido bajo la constitución de Luisiana (1812). En su opinión, el problema central del référé au legislatif era que comprometía el principio de separación de poderes, al asignarle funciones judiciales a la legislatura. Dichos argumentos eran muy similares a aquellas usadas por Blackstone, quien caracterizaba al référé como una fuente de "parcialidad" y de "opresión". ${ }^{85}$

En el mismo informe de los redactores del Código de Luisiana, a los jueces se les describían como aquel "órgano para dar voz (...) a lo que ha decretado el poder legislativo". ${ }^{86}$ La única discreción otorgada a los jueces, se decía, era aquella que les permitía "determinar el significado del Derecho cuando se (ponía) en $d u d a$ " ${ }^{87}$ Nuevamente, estas propuestas reflejan las ideas de Blackstone perfectamente, y en particular, su sugerencia de recurrir a la razón o al espíritu de la ley, lo cual involucraba un elemento de discreción judicial, se reservaba para los casos en los que el significado de la letra de la ley era "ambigua". ${ }^{8}$

La influencia significativa de Blackstone sobre el Código Civil de Luisiana se evidencia por una serie de factores que deben ser considerados conjuntamente: las marcadas similitudes de redacción entre el Código de Luisiana y los Comentarios de Blackstone ${ }^{89}$ la disponibilidad de dichos Comentarios para los redactores del Código

\footnotetext{
82 Ver sección 2.2 anterior.

83 Ver sección 2.2 anterior

84 Livingston et. al. (1823), p. 5.

85 Blackstone (1783), p. 59.

86 Livingston et. al. (1823), p. 8. Énfasis agregado por el autor.

87 Livingston et. al. (1823), p. 8.

88 Blackstone (1783), p. 60.

89 Ver sección 2.1 anterior.
} 
Civil de Luisiana, ${ }^{90}$ el hecho de que dichos redactores reconocían haber utilizado las "abundantes fuentes" de jurisprudencia inglesa, ${ }^{91}$ y la clara influencia de Blackstone en otras áreas del Código de Luisiana. ${ }^{92}$ Finalmente, tal como veremos en la siguiente sección, todas las demás posibles fuentes de inspiración (sea que fuesen mencionadas por los redactores del Código de Luisiana o por historiadores del derecho), cuando se consideran en su totalidad, se diferencian de las ideas de Blackstone, y de las disposiciones del Código de Luisiana.

\section{DESGARTANDO GANDIDATOS ALTERNATIVOS}

\subsection{La Tradición del Derecho Givil y el Código Givil de Luisiana}

Tal como se mencionó anteriormente, ${ }^{93}$ las dudas sobre el significado de la influencia de Blackstone se han expresado, y adicionalmente, los redactores del Compendio de Luisiana (1808), en este sentido (Moreau Lislet), han indicado algunas otras posibles fuentes de inspiración. En teoría, los escritos de Jean Domat y Samuel Pufendorf, y el derecho francés y español, podrían haber sido fuentes alternativas de inspiración para las reglas de interpretación de la ley del Código Civil de Luisiana. Por lo tanto, es menester examinar si estas otras fuentes eran una fuente de inspiración igual o más relevantes que Blackstone. ${ }^{94}$

\subsection{Jean Domat}

En el De la Vergne Volume, ${ }^{95}$ los redactores de las reglas de interpretación de la ley para el Compendio de Luisiana de 1808, hicieron varias anotaciones conectando aquellas reglas con los escritos de Jean Domat (1625-1696). Domat fue un jurista francés de la escuela del derecho natural, quien fue el autor de El Derecho Civil en su Orden Natural, publicado inicialmente en 1689. ${ }^{96}$ En él, entre otros asuntos, Domat expresó sus ideas sobre la interpretación de la ley en la forma de reglas. La siguiente tabla presenta las reglas de Domat, seguido por los artículos del Código de Luisiana relacionados a ellas, de acuerdo con los apuntes de Moreau Lislet:

90 FrankLin (1940-1941), p. 405.

91 Livingston et. al. (1823), p. 6.

92 KNÜTeL (1995-1996), pp. 1458-1459.

93 Ver Sección 1.4 anterior.

94 Rolf Knütel, destacado jurista alemán, ha señalado que la fuente de inspiración para el Art. 13 del Código Civil de Luisiana era una regla del derecho romano sobre la interpretación de testamentos (D. 32.25.1). Sin embargo, no proporciona una explicación para las demás disposiciones sobre interpretación de la ley del Código de Luisiana. Cfr. KNÜTeL (1995-1996), p. 1458.

95 Ver sección 1.4 anterior

96 Domat (1689). 


\begin{tabular}{|c|c|}
\hline $\begin{array}{l}\text { Textos de Domat indicados por el redactor del } \\
\text { Compendio de Luisiana }{ }^{97}\end{array}$ & Código Civil de Luisiana \\
\hline $\begin{array}{l}\text { Regla XII de Domat: "si las palabras de una ley expre- } \\
\text { san el sentido y la intención de una ley de forma clara, } \\
\text { debemos aferrarnos a ello. Pero si el sentido real de una } \\
\text { ley no se puede entender suficientemente (...) o siendo } \\
\text { claro el sentido de la Ley, presenta inconveniencias para } \\
\text { el bien común; debemos en este caso recurrir al Príncipe, } \\
\text { para saber de él su intención (...)". }\end{array}$ & \multirow{2}{*}{$\begin{array}{l}\text { Art. } 13 \text { Cuando una ley es cla- } \\
\text { ra y libre de toda ambigüedad, } \\
\text { la letra de la misma no se debe } \\
\text { desestimar, bajo el pretexto de } \\
\text { estar buscando el espíritu de la } \\
\text { misma }\end{array}$} \\
\hline $\begin{array}{l}\text { Regla XIX de Domat: "Si las dificultades que surjan en } \\
\text { la interpretación de una Ley (...) se pueden explicar por } \\
\text { un uso antiguo, debemos aferrarnos al sentido declarado } \\
\text { por la Práctica constante". }\end{array}$ & \\
\hline $\begin{array}{l}\text { Regla IX de Domat: "Las obscuridades, ambigüedades y } \\
\text { otros defectos de expresión, que puedan conllevar a que } \\
\text { el sentido de una Ley sea ambiguo (...) se debe resolver } \\
\text { por el sentido que es el más natural, que tenga la mayor } \\
\text { relación al Tema, el cual sea el más conforme a la inten- } \\
\text { ción del legislador, y el que más calce con la Equidad } \\
(. . .) \text { ". }\end{array}$ & $\begin{array}{l}\text { Art. 14. Generalmente las pa- } \\
\text { labras de una ley se deben en- } \\
\text { tender según su significado más } \\
\text { conocido y usual, sin atender } \\
\text { tanto a las sutilezas de las reglas } \\
\text { gramaticales, como al uso gene- } \\
\text { ral y popular de los términos. }\end{array}$ \\
\hline $\begin{array}{l}\text { No existe referencia para este artículo en el Volumen } \\
\text { De la Vergne. }\end{array}$ & $\begin{array}{l}\text { Art. 15. Los términos de las ar- } \\
\text { tes, o términos técnicos y frases, } \\
\text { se deben interpretar según el } \\
\text { significado recibido y la acep- } \\
\text { ción de entre los doctos en el } \\
\text { arte, el oficio, o la profesión a } \\
\text { los que se refieren. }\end{array}$ \\
\hline
\end{tabular}

Regla X de Domat: "Para entender correctamente el sentido de una ley, debemos considerar todas las palabras de ella, y su Preámbulo, si lo tuviera, para que podamos juzgar el significado de la ley por sus motivos y por el tenor completo de lo que prescribe (...) Así, sería transgredir las Reglas y el Espíritu de las leyes, el hacer uso (...) de cualquier parte de una Ley tomada separadamente del resto (...)".

Regla XI de Domat: "Si se omite cualquier cosa de una ley que es esencial para ella, o que sea una consecuencia necesaria de su disposición, y que tienda a darle a la ley su efecto completo, según su motivación, podemos en este caso proporcionar lo que falte en la expresión, y extender la disposición de la ley a lo que se incluya dentro de su intención, aunque no se exprese en palabras".

97 Cita de DOMAT (1737), pp. 7 y sig. En el Libro Preliminar Título 1 Sección 2 (de las Reglas Generales de Derecho), Domat proporciona veintinueve reglas, enumeradas desde el I al XXIX, las 


\begin{tabular}{|c|c|}
\hline con otras leyes que puedan & $\begin{array}{l}\text { sen so } \\
\text { terpre } \\
\text { ellas; } 1 \\
\text { ser ton } \\
\text { cación }\end{array}$ \\
\hline $\begin{array}{l}\text { de- } \\
\text { lan } \\
\text { uó } \\
\text { hás } \\
\text { el } \\
\text { la- }\end{array}$ & $\begin{array}{l}\text { Art. 18. La forn } \\
\text { tiva de descubı } \\
\text { cado de una le } \\
\text { nes sean ambig } \\
\text { razón y el espí } \\
\text { que indujo a } 1 \\
\text { mulgarla. }\end{array}$ \\
\hline
\end{tabular}

Tal como demuestra la tabla precedente, existía cierto paralelo entre las reglas propuestas por Domat y aquellas del Código Civil de Luisiana. Ambos establecían que se debía seguir la ley en los casos en los que el lenguaje era claro, aun cuando se describía la "claridad" de forma distinta (Artículo 13 del Código de Luisiana), que el significado asignado a las palabras debería ser aquel que fuese natural (común) (Artículo 14 del Código de Luisiana), que el contexto y las leyes in pari materia debían ser consultadas (Artículos 16 y 17 del Código de Luisiana), y que el espíritu de la ley se debía tomar en consideración en caso de ambigüedad de la letra de la misma (Artículo 18 del Código de Luisiana). Sin embargo, un conjunto de diferencias claves aparecen del panorama completo de ideas propuestas por Domat respecto de la materia de interpretación de la ley. ${ }^{98}$ A resumidas cuentas: a diferencia de Blackstone y el Código de Luisiana, Domat no favorecía el darle prioridad incondicional a una interpretación literal, ${ }^{99}$ y él sugería una interpretación del soberano cuando se presentasen dudas (référé au legislatif). ${ }^{100}$

En relación con la primera diferencia, mientras que el Código de Luisiana establecía que "cuando sea clara la ley (...) la letra de la misma no debiese ser desestimada" (Artículo 13), Domat planteaba que, en algunos casos, aun cuando fuese "claro el sentido de la ley", "si surgiera de la misma alguna inconveniencia para el bien común", no se debería seguir la letra, y el príncipe (el legislador), debiera ser consultado (Regla XII de Domat). Esta idea fue reafirmada por Domat en otra parte del mismo capítulo:

cuales son mencionadas en la De la Vergne Volume. Énfasis agregado por el autor.

98 Las diferencias entre las ideas de Domat y las reglas de interpretación de la ley del Código Civil Chileno han sido analizadas detalladamente por Antonio Bascuñán, en BAScuñán RodRíguez (2014), pp. 263-349.

99 Domat (1737), Regla XII.

100 Domat (1737), Regla XII. 
Cuando suceda que el sentido de la ley, sin importar cuán clara aparezca en sus palabras, nos conduzca a decisiones que sean injustas, (dicho evento) nos obliga a descubrir (...) no lo que dice la ley, sino lo que significa. ${ }^{101}$

Así, según Domat, la interpretación literal no debería prevalecer siempre por sobre otros métodos. El intérprete podría justificadamente buscar interpretaciones no-literales cuando esté convencido de que el significado literal sea injusto o contrario al bien común. A contrario sensu, el Artículo 13 del Código de Luisiana prohíbe la desestimación de la letra de la ley bajo el "pretexto de buscar su espíritu". Esta es una notable diferencia entre Domat, por un lado, y Blackstone y el Código de Luisiana, por el otro. Tal como se ha mencionado anteriormente, Blackstone y el Código de Luisiana establecían el recurrir a la razón (espíritu) de la ley en casos en los que el significado de la letra fuese ambiguo. ${ }^{102}$ Interesantemente, Gabriel Ocampo, miembro de una comisión gubernamental que revisó el borrador del Código Civil Chileno, reconoció en una nota manuscrita en su borrador del Código, la existencia de esta diferencia entre Domat y los Códigos de Luisiana y de Chile. ${ }^{103}$ En el margen del artículo 19 del Código Civil Chileno (el cual dice: "cuando el sentido de la ley es claro, no se desatenderá su tenor literal, a pretexto de consultar su espíritu”), Ocampo comenta: "Domat parece profesar una opinión contraria". ${ }^{104}$ Esto es relevante por dos motivos. Primeramente, indica que algunos contemporáneos estaban al tanto de las diferencias entre el Código de Luisiana y de Chile, y las ideas de Domat. Segundo, la anotación de Ocampo seguramente refleja el hecho de que la diferencia fue discutida en reuniones de la comisión con Andrés Bello, redactor del Código Civil Chileno, y por ende la desviación de Domat fue algo consciente.

La segunda diferencia con Domat fue que, aun cuando Blackstone y el Código de Luisiana se oponían al método de référé au legislatif, Domat argumentaba en su favor:

Si el verdadero sentido de una ley no puede ser suficientemente comprendida (...) nosotros debemos tener recurso en este caso al Príncipe, para saber de él mismo su intención. ${ }^{105}$

Por lo tanto, aun cuando exista una similitud entre las ideas de Domat, y aquellas de Blackstone y el Código de Luisiana, la similitud se disuelve una vez que el panorama completo de reglas sobre interpretación de la ley se toma en considera-

101 Domat (1737), p. 7. Énfasis agregado por el autor.

102 Domat también lo sugirió en su Regla IX. El punto es que admitió lo mismo cuando la letra de la ley fuese clara, pero injusta o inconveniente.

103 La copia con anotaciones del Código Civil Chileno de Ocampo se encuentra bajo custodia de la Universidad de Chile. Consultado en libros.uchile.cl/568 el 2 de enero del 2017.

104 En español, la versión original es "Domat parece profesar una opinión contraria".

105 Domat (1737), Regla XII. 
ción. Domat apoyaba al référé au legislatif y al modelo no-jerárquico de interpretación, mientras que Blackstone y el Código de Luisiana apoyaban lo opuesto. Como tal, Domat podría haber sido una inspiración parcial para el Código de Luisiana, pero no la inspiración más significativa.

\subsection{Derecho español}

Los redactores de las reglas sobre interpretación de la ley para el Compendio de Luisiana de 1808, también nombraron una serie de reglas del derecho español en relación con el Artículo 13 del Compendio. La siguiente tabla compara dichas reglas del derecho español con las del Código Civil de Luisiana:

\begin{tabular}{|c|c|}
\hline Derecho Español & Código Civil de Luisiana \\
\hline Ley 14 Título 1 Partida $1^{106}$ & Art. 13 del Código Civil de Luisiana \\
\hline $\begin{array}{l}\text { En caso de que el significado de una ley sea du- } \\
\text { dosa, debido o a un error en su redacción o a un } \\
\text { error del lector, cuando el significado deba ser } \\
\text { explicado correctamente y la verdad de la ley } \\
\text { deba ser comprendida, esto se puede hacer sola- } \\
\text { mente por quien escribió la ley. }\end{array}$ & $\begin{array}{l}\text { Art. } 13 \text { Cuando una ley es clara y libre } \\
\text { de toda ambigüedad, la letra de la mis- } \\
\text { ma no se debe desestimar, bajo el pre- } \\
\text { texto de estar buscando el espíritu de la } \\
\text { misma }\end{array}$ \\
\hline Ley 4 Título 33 Partida $7^{107}$ & \\
\hline $\begin{array}{l}\text { Nadie más que el Rey puede explicar o declarar } \\
\text { la ley cuando exista duda sobre las palabras o su } \\
\text { comprensión. }\end{array}$ & \\
\hline Ley 3 Título 1 Libro 2 Recopilación Castellana ${ }^{108}$ & \\
\hline $\begin{array}{l}\text { Y dado que le pertenece al Rey y él tiene poder } \\
\text { para promulgar, interpretar y declarar la ley }(\ldots) \\
\text { estimamos que es apropiado que (...) si alguna } \\
\text { declaración o interpretación se requiera }(\ldots) \text {, } \\
\text { Nosotros (el Rey) lo deberá hacer. }\end{array}$ & \\
\hline
\end{tabular}

106 LóPez (1555), p. 8. El texto en español antiguo dice lo siguiente: "Dubdosas seyendo las leyes por yerro de escriptura, o por mal entendimiento del que las leyesse porque debiessen de ser bien espaladinadas, e fazer entender la verdad dellas: esto non puede ser por otro fecho sino por aquel q las fizo o por otro q sea en su logar, que aya poder de las fazer de nuevo, e guardar aquellas fechas".

107 López (1555), p. 97. El texto en español antiguo dice: 'Espaladinar, nin declarar, non deve ninguno, nin puede las leyes si non el Rey quando dubda acaeciesse sobre las palabras, o el entendimiento de ellas'.

108 Recopilación de las leyes destos Reynos hecha por mandado de la Majestad Católica del Rey Don Philippe segundo Nuestro Señor (Alcalá de Henares 1569), pp. 45-46. La Fuente es una ley promulgada por el Rey 
Las tres reglas del derecho español mencionadas por el redactor del Compendio de Luisiana de 1808 establecían que la interpretación de la ley estaba reservada para el Rey (référé au legislatif). Esto claramente contradecía el Código de Luisiana, el cual no emplea la utilización de esta idea. Es más, estas reglas del derecho español estaban en oposición a la opinión de Blackstone, y de los redactores del Código de Luisiana. ${ }^{109} \mathrm{La}$ única explicación disponible para dar cuenta de la mención por parte de Moreau Lislet de estas es que se hizo para enfatizar su divergencia. Esto no es sorprendente: John W. Cairns, un prominente historiador del derecho, ha notado que las menciones en De la Vergne Volume apuntan a "disposiciones similares, equivalentes, y contradictorias en el derecho romano y español, y no a fuentes". ${ }^{110}$ Así, podemos descartar el derecho español como fuente principal de inspiración para las reglas de interpretación de la ley del Código Civil de Luisiana, aun cuando fue mencionado por el redactor.

\subsection{Samuel Pufendorf}

Ahora debemos dirigir nuestra atención a una sugerencia presentada por el destacado historiador chileno, Alejandro Guzmán Brito. Según él, aun cuando es claro que el redactor de las reglas del Compendio de Luisiana sobre la construcción de la ley utilizó las ideas de Blackstone, no había nada original en Blackstone con lo cual se pudiera beneficiar el Código Civil de Luisiana. ${ }^{111}$ En la opinión de Guzmán Brito, las ideas propias de Blackstone estaban sustancialmente formadas por una tradición del derecho civil, por medio de los escritos de Samuel Pufendorf. Hay mucha verdad en esta afirmación: en cuanto a la materia de interpretación de la ley, así como con muchos otros temas, Blackstone consultó y siguió parcialmente a autores civilistas. Esta era una característica general de sus Comentarios sobre las leyes de Inglaterra. Más específicamente, en el área de la interpretación de la ley, Blackstone dependía en gran medida de las obras de Samuel Pufendorf (1632 - 1694), un destacado jurista alemán de la escuela del derecho natural. En su libro, De fure Naturae et Gentium (Sobre el Derecho Natural y de las Naciones), el cual fue publicado inicialmente en 1672, Pufendorf dedicó un capítulo a la interpretación de la ley, explícitamente siguiendo a Hugo Grocio, otro destacado miembro de la escuela del derecho natural. Existían varias coincidencias en el pensamiento de Blackstone y de Pufendorf. En verdad, parece ser claro que muchas de las ideas y frases fueron tomadas casi literalmente de las obras de Pufendorf, tales como las reglas sobre el significado común y técnico de las palabras, porciones de la regla sobre la intención de la legislatura, y muchos ejemplos más. Sin embargo, a pesar de estas similitudes, también existían importantes diferen-

\footnotetext{
Alfonso en 1386. El texto en español antiguo dice "Y porq al Rey pertenece y a poder de hazer fueros y leyes y de las interpretar y declarar [...] tenemos por bien que si en los dichos fueros .... en algunas leyes $[\ldots]$ fuere menester declaración y interpretación $[\ldots]$ que nos lo haremos".

109 Ver Sección 2.3 anterior.

110 Cairns (2009), pp. 77-8.

111 GuZMán Brito (2009).
} 
cias entre las visiones de estos dos escritores. Aquellas diferencias se presentan si, en vez de enfocarse en aquellos elementos individuales, tomamos en consideración el panorama completo.

En primer lugar, el método de interpretación presentado por Pufendorf era un método no-jerárquico, en el que los elementos literales y no-literales se podrían aplicar de manera simultánea. Según Pufendorf:

El verdadero fin y diseño de interpretación es el recopilar la intención del hombre de las señales más probables (...) palabras, y otras conjeturas, las cuales podrían ser consideradas separadamente, o ambas juntas. ${ }^{12}$

En segundo lugar, existía un desacuerdo más crucial entre los dos escritores concerniente a la relación entre una ley y la razón de su promulgación. Pufendorf, al igual que Blackstone, recomendaba cautela en el uso de la equidad para fines de interpretación. Sin embargo, admitía que podríamos actuar "contrariamente" a la "letra de la ley", si "encontramos que la adhesión precisa a la letra es (...) repugnante para el Derecho de Dios o de la Naturaleza. A esto, ningún hombre puede estar obligado". ${ }^{13}$ Esta declaración de un escritor de la escuela del derecho natural no es sorprendente. Sin embargo, tal como se mencionó anteriormente, ${ }^{114}$ Blackstone estaba en total desacuerdo:

Si el Parlamento promulgará activamente a que se haga algo, que no sea razonable, no conozco ningún poder en la forma ordinaria de la constitución, que esté investida con la autoridad de controlarla. ${ }^{115}$

Así, según Blackstone, una ley emitida por el Parlamento debiera ser obedecida, sin importar cuán "poco razonable" sea; o, en otras palabras, cuán injusta pareciera ser. Esta propuesta ha llevado a varios autores a cuestionar la consistencia de la adherencia de Blackstone a las doctrinas del derecho natural. En particular, Gareth Jones ha puesto en duda la posibilidad de reconciliar las aparentes ideas de Blackstone del derecho natural con su concepto del soberano "no-controlado" (Parlamento). ${ }^{116}$ Recurrir a la razón de la ley fue confinado por Blackstone a aquellos casos en los que fuesen "ambiguas las palabras" (es decir, casos que no se pudiesen resolver bajo la regla del significado llano).

Finalmente, una comparación de los siguientes pasajes de los escritos de $\mathrm{Pu}$ fendorf y Blackstone refleja más diferencias en sus enfoques sobre la interpretación.

\footnotetext{
112 Pufendorf (1717), p. 51.

113 Pufendorf (1717), p. 315.

114 Sección 2.2 anterior.

115 Blackstone (1783), p. 91.

116 Jones (1973), p. xxxviii.
} 
Mientras que Pufendorf consideraba que la razón o el espíritu de la ley es aquello "que más nos ayuda" para la interpretación, Blackstone recurría al mismo solamente cuando "fuesen ambiguas las palabras".

\begin{tabular}{|c|c|}
\hline Pufendorf & Blackstone \\
\hline $\begin{array}{l}\text { Pero aquello que nos ayude más a descubrir } \\
\text { el verdadero significado de la ley es la razón } \\
\text { de ella, o la causa que inspiró al legislador a } \\
\text { promulgarla. }{ }^{117}\end{array}$ & $\begin{array}{l}\text { Pero, a fin de cuentas, la forma más uni- } \\
\text { versal y efectiva de descubrir el verdadero } \\
\text { significado de una ley, cuando las palabras son } \\
\text { ambiguas, es considerando la razón y el espí- } \\
\text { ritu de ella. }{ }^{118}\end{array}$ \\
\hline
\end{tabular}

Esta diferencia es destacable. A lo largo de este capítulo, Blackstone claramente siguió el texto de Pufendorf. Sin embargo, al llegar a la discusión de Pufendorf sobre el espíritu de la ley, Blackstone tomó cuidado especial de explicar que el uso del mismo debería limitarse a los casos en los que las palabras fuesen ambiguas, agregando de esta forma un requisito que no se encontraba presente en el texto de Pufendorf.

En resumen, Guzmán Brito está completamente en lo correcto al reconocer el uso extensivo que hizo Blackstone de los escritos de Pufendorf en cuanto a materia de interpretación. Sin embargo, existía una crucial diferencia entre las obras de ambos teóricos: Blackstone se inclinaba más hacia el método literal de interpretación, como consecuencia de su preferencia por el derecho proveniente del Parlamento, mientras que Pufendorf estaba preparado para desestimar la interpretación literal, en casos donde resultase en una violación del derecho natural. Para Blackstone, recurrir a la razón de la ley o a la intención de la legislatura, era un método meramente subsidiario. Este fue el enfoque adoptado por el Código Civil de Luisiana también (Artículo 18). Así, contraria a la opinión de Guzmán Brito, Blackstone no transcribió los textos de Pufendorf meramente, sino que contribuyó con otras ideas y distintas.

\subsection{Derecho francés}

Dentro de las ideas jurídicas francesas, existía una diferencia entre el Proyecto Francés del Código Civil de 1800, el cual nunca fue promulgado, y el Código Civil Francés, promulgado en 1804. Aun cuando el Proyecto Francés sí incluía disposiciones referentes a la interpretación judicial de la ley, el Código Civil Francés (1804) no las incluía. Por ende, solamente podría haber servido el Proyecto Francés como inspiración para el Código Civil de Luisiana. Moreau Lislet no lo mencionó en el De la Vergne Volume, pero la similitud entre el Artículo 13 del Código de Luisiana y el Artículo V Título V del Libro Preliminar del Proyecto Francés han conducido a los juristas a defender dicha influencia, razonablemente. ${ }^{119}$

117 Pufendorf (1717), p. 397

118 Blackstone (1783), p. 61. Énfasis agregado por el autor.

119 GuZMán Brito (2009). 


\begin{tabular}{l|c}
\hline $\begin{array}{c}\text { Artículo V, Libro Preliminar del Libro del } \\
\text { borrador del Código Civil Francés del Año } \\
\text { VIII }(1800)^{120}\end{array}$ & Código Civil de Luisiana \\
\hline $\begin{array}{l}\text { Artículo V. Cuando la ley sea clara, su letra no } \\
\text { debe ser eludida bajo el pretexto de buscar su } \\
\text { espíritu; y en la aplicación de una ley obscu- } \\
\text { ra, se deberá preferir su sentido más natural y } \\
\text { menos defectuoso. }\end{array}$ & $\begin{array}{l}\text { Art. } 13 \text { Cuando una ley es clara y libre de } \\
\text { se debe desestimar, bajo el pretexto de es- } \\
\text { tar buscando el espíritu de la misma. }\end{array}$ \\
\hline
\end{tabular}

Los paralelos entre la primera porción del Artículo 13 del Código de Luisiana y el Artículo V del Proyecto Francés son obvios. Ambos establecían que, cuando el significado de una ley fuese claro, este significado no podría ser eludido bajo el pretexto de buscar el espíritu de dicha ley. Además, así como el Artículo 16 del Código Civil de Luisiana, el Artículo VI del borrador del Código Civil Francés prescribía un análisis contextual. ${ }^{121}$ No obstante, las coincidencias ahí terminan. Por ejemplo, a diferencia del Código Civil de Luisiana, el Proyecto Francés mantenía silencio en cuanto a la cuestión de cómo deberían asignarle significado los jueces a las palabras de la ley, y todas las demás disposiciones del Proyecto Francés no tenían paralelo con el Código de Luisiana. Sin embargo, aun cuando existían diferencias entre muchas de las reglas detalladas de estos dos documentos, la concepción general de la interpretación de la ley del Proyecto Francés era similar a la del Código de Luisiana.

Adicionalmente, existía otra coincidencia con el Código de Luisiana: el Proyecto Francés (1800) no adoptó el método de référé au legislatif, una piedra angular del derecho francés pos-revolucionario, el objetivo del cual era la subyugación del poder judicial. Una Ley con fecha de agosto de 1790 obligaba a las cortes a "dirigirse a la legislatura cuando lo estimen necesario (...) para interpretar la ley". ${ }^{122}$ Esto no era algo nuevo: bajo el ancien regime, una Ordonnance de Reformation de la fustice Civile con fecha de abril de 1667 establecía que la interpretación de la ley estaba reservada para el soberano. ${ }^{123}$ Sin embargo, en 1800, simultáneo a la redacción del Proyecto Francés de 1800, el référé au legislatif había perdido su popularidad. En ese mismo año, el référé au legislatif fue abandonado, y durante un período breve, el Cour de Cassation, considerado por los contemporáneos francés como un "mal necesario", se erigió como la última palabra respecto de la interpretación. ${ }^{124}$

El modelo del Proyecto Francés (1800), tan similar en cuanto a su filosofía con el Código de Luisiana, tuvo una vida muy corta, y nunca pasó a ser ley positiva. Primero, el Código Civil Francés promulgado en 1804 no incluía reglas sobre

120 Commission nommée par le Gouvernement le 24 Thermidor an VIII, Projet de Code Civil (Chez Emery, Ventôse an IX-1801).

121 Art. VI: "Pour fixer le vrai sens d'une partie de la loi, il faut en combiner et en reúnir toutes les dispositions".

122 Dawson (1968), pp. 375-6.

123 Planiol y Ripert (1997), p. 25.

124 Ghestin y Gobeaux (1994), pp. 372-3. 
interpretación de la ley. En segundo lugar, tres años más tarde, en 1807, el référé au legislatif fue re-introducido al derecho francés bajo la forma de un référé para el poder ejecutivo. ${ }^{125}$ El resultado fue que, para cuando se estaba redactando el Compendio de Luisiana de 1808, el derecho francés difirió marcadamente del modelo adoptado en Luisiana.

En resumen, la filosofía general sobre la interpretación de la ley en el Proyecto Francés (1800), el cual nunca pasó a ser ley positiva, ciertamente coincide con la del Código de Luisiana; pero aparte de eso, el derecho positivo francés tuvo poca influencia sobre el Código Civil de Luisiana. Pocos años después de la redacción del Proyecto, el derecho francés había adoptado una solución distinta: ninguna regla alguna que rigiera la interpretación judicial (Código Civil de 1804), y un retorno al référé au legislatif (1807). Naturalmente, el ideal político de que la legislatura debiese prevalecer por sobre el poder judicial, tenía a muchos partidarios en Francia, al igual que en Luisiana, a lo largo del siglo diecinueve: la escuela exegética francesa en su totalidad, es clara evidencia de ello. ${ }^{126}$ La diferencia crucial con Luisiana no era una de filosofía política, sino de la forma de implementación de dicho ideal al derecho.

\subsection{Resumen}

En las secciones precedentes, sostuve que Blackstone fue la fuente de inspiración más significativa para las reglas de interpretación de la ley del Código Civil de Luisiana, al demostrar que ninguna de las otras alternativas podría haber tenido una influencia similar. Los comentarios de Blackstone proporcionaron la redacción de las disposiciones, al igual que la amplia concepción de interpretación adoptada por el Código de Luisiana. Dicho modelo tiene tres características principales: (a) tenía un enfoque jerárquico: la regla del significado llano o literal prevalecía incondicionalmente por sobre la interpretación basada en el espíritu de la ley o en la intención de la legislatura, en una manera distinta a los enfoques de Domat y Pufendorf; (b) no adoptaba el método de référé au legislatif, a contrario sensu de los enfoques de Domat, del derecho español y del derecho francés, siendo así más coherente en este respecto para el principio de separación de poderes; ${ }^{: 127}$ e (c) incluía detalladas reglas jurídicas que guiaban en la interpretación judicial, a diferencia del Código Civil Francés de 1804 y del derecho español (aunque muy similar a Blackstone, Domat y Pufendorf).

Entre estas fuentes consideradas anteriormente como posibles influencias para el Código de Luisiana, el modelo más similar al de Blackstone fue la del efímero Proyecto Francés de 1800. Primero, ambos fueron motivados por el objetivo polí-

125 Ghestin y Gobeaux (1994), pp. 372-3; Dawson (1968), p. 379. Después de una reforma subsiguiente en 1828, el référé au legislatif continuó en vigencia hasta que fue derogado mediante ley promulgada el 1 de abril de 1837.

126 Dawson (1968), pp. 392-4.

127 En el caso del derecho francés, con la salvedad de un período breve entre 1800 y 1807, tal como se explica en la Sección 2.2. 
tico de restringir la discreción judicial. Segundo, el Proyecto Francés inspiró uno de los artículos del Código de Luisiana (Artículo 13). Finalmente, aun tomando en consideración que casi todas las demás reglas eran distintas a las del Código de Luisiana, no se puede negar que, en términos generales, Blackstone y el Proyecto Francés tuvieron un enfoque similar para la interpretación de la ley. Sin embargo, desde un punto de vista histórico, existe una diferencia clave entre ellas. Mientras que el Proyecto Francés representó un fenómeno efímero dentro de las ideas jurídicas francesas, las ideas de Blackstone pasaron a ser una característica central del derecho inglés.

Así, el Código Civil de Luisiana, por medio de Blackstone, adoptó una característica central del derecho inglés del siglo diecinueve (la regla del significado llano), el cual se mantenía en marcado contraste con tanto la tradición civilista (Pufendorf, Domat y el derecho español) y la falta de regulación de interpretación en el Código Civil francés (1804). Lo mismo se puede decir respecto del Código Civil Chileno y sus secuelas (Ecuador, Uruguay y Colombia), los cuales fueron inspirados por el Código Civil de Luisiana.

Los contemporáneos estaban al tanto de que Blackstone y el derecho inglés coincidían en cuanto a la materia de interpretación de la ley. Para los inicios del siglo diecinueve, James Kent, un autor angloamericano muy leído en Sudamérica, había escrito que la deferencia absoluta por el derecho proveniente del Parlamento era un "principio del derecho inglés", e identificaba a Blackstone como su mayor defensor. ${ }^{128}$ Por medio de Kent, muchos autores sudamericanos podrían haberse enterado de esta característica central del derecho inglés, y que Blackstone podría ser utilizado como una fuente relevante de inspiración para dicha área. Por ejemplo, Bello y Narvaja, los redactores del Código Civil chileno y uruguayo, eran lectores de Kent y partidarios convencidos del literalismo en asuntos de interpretación de la ley. En la siguiente sección, examinaremos dichos aspectos al explorar la influencia indirecta de Blackstone en algunos Códigos Civiles sudamericanos.

\section{INFLUENGIA INDIREGTA DE BLAGKSTONE SOBRE LOS GÓDIGOS GIVILES SUDAMERICANOS}

\subsection{Interpretación de la ley en el Código Givil chileno}

Los artículos 19 al 22 del Código Civil chileno (1855) versan sobre la interpretación de la ley. Tal como reconoció explícitamente Andrés Bello, ${ }^{129}$ redactor del Código, dichas reglas fueron inspiradas por el Código Civil de Luisiana (1825). En la siguiente tabla, se comparan de forma correlativa los artículos del Código Civil de Luisiana y del Código Civil chileno, y se destacan las diferencias:

$128 \operatorname{KenT}$ (1854), p. 493.

129 BeLLo (1981), pp. 41-42. 


\begin{tabular}{|c|c|}
\hline Código Civil de Luisiana & Código Civil Chileno ${ }^{130}$ \\
\hline $\begin{array}{l}\text { Art. } 13 \text { Cuando una ley es clara y libre de } \\
\text { toda ambigüedad, la letra de la misma no } \\
\text { se debe desestimar, bajo el pretexto de estar } \\
\text { buscando el espíritu de la misma }\end{array}$ & $\begin{array}{l}\text { Art. 19. (Primera parte) })^{131} \text { : Cuando el sentido } \\
\text { de la ley es claro, no se desatenderá su tenor } \\
\text { literal, a pretexto de consultar su espíritu. }\end{array}$ \\
\hline $\begin{array}{l}\text { Art. 14. Generalmente las palabras de una } \\
\text { ley se deben entender según su significado } \\
\text { más conocido y usual, sin atender tanto a } \\
\text { las sutilezas de las reglas gramaticales, como al } \\
\text { uso general y popular de los términos. }\end{array}$ & $\begin{array}{l}\text { Art. 20. Las palabras de la ley se entenderán } \\
\text { en su sentido natural y obvio, según el uso } \\
\text { general [popular] de las mismas palabras [su- } \\
\text { tilezas de las reglas gramaticales]; pero cuando } \\
\text { el legislador las haya definido expre- } \\
\text { samente para ciertas materias, se les } \\
\text { dará en éstas su significado legal. }\end{array}$ \\
\hline $\begin{array}{l}\text { Art. 15. Los términos de las artes, o térmi- } \\
\text { nos técnicos y frases, se deben interpretar } \\
\text { según el significado recibido y la acepción } \\
\text { de entre los doctos en el arte, el oficio, o la } \\
\text { profesión a los que se refieren. }\end{array}$ & $\begin{array}{l}\text { Art. 21. Las palabras técnicas de toda ciencia } \\
\text { o arte se tomarán en el sentido que les den los } \\
\text { que profesan la misma ciencia o arte; a menos } \\
\text { que aparezca claramente que se han tomado } \\
\text { en sentido diverso. }\end{array}$ \\
\hline $\begin{array}{l}\text { Art. 16. Cuando las palabras de una ley } \\
\text { sean ambiguas, su significado podrá ser } \\
\text { buscado examinando el contexto con el } \\
\text { cual se pueda comparar la palabra, frase u } \\
\text { oración ambigua, con la finalidad de esta- } \\
\text { blecer su significado real. }\end{array}$ & $\begin{array}{l}\text { Art. } 22 \text { inc. 1: El contexto de la ley servirá } \\
\text { para ilustrar el sentido de cada una de sus } \\
\text { partes, de manera que haya entre todas ellas } \\
\text { la debida correspondencia y armonía. }\end{array}$ \\
\hline $\begin{array}{l}\text { Art. 17. Leyes pari materia, o que versen so- } \\
\text { bre el mismo tema, deben ser interpretadas } \\
\text { haciendo referencia entre ellas; lo que es } \\
\text { claro en una ley puede ser tomado a modo } \\
\text { de auxiliar la explicación de lo que es du- } \\
\text { doso en la otra. }\end{array}$ & $\begin{array}{l}\text { Art. } 22 \text { inc. 2: Los pasajes obscuros de una } \\
\text { ley pueden ser ilustrados por medio de otras } \\
\text { leyes, particularmente si versan sobre el mis- } \\
\text { mo asunto. }\end{array}$ \\
\hline $\begin{array}{l}\text { Art. } 18 \text { La forma más universal y efectiva } \\
\text { de descubrir el verdadero significado de } \\
\text { una ley, cuando sus expresiones sean ambi- } \\
\text { guas, es considerando la razón y el espíritu } \\
\text { de ella, o la causa que indujo a la legislatura } \\
\text { para promulgarla. }\end{array}$ & $\begin{array}{l}\text { Art. } 19 \text { inc. 2: Pero bien se puede, para in- } \\
\text { terpretar una expresión obscura de la ley, } \\
\text { recurrir a su intención o espíritu, claramente } \\
\text { manifestados en ella misma, o en la historia } \\
\text { fidedigna de su establecimiento. }\end{array}$ \\
\hline
\end{tabular}

Así, al igual que el Código de Luisiana, el Código Civil chileno no le obligaba al juez a consultar con la legislatura en caso de dudas: no existía référé au legislatif. Ambos códigos adoptaron un modelo jerárquico bajo el cual prevalecería el método literal, y ambos incluían una serie de reglas detalladas sobre la interpretación, intentando limitar la discreción judicial.

130 Texto de Luisiana omitido por Bello. En negritas: texto agregado por Bello.

131 En la tabla anterior, el Art. 19 se divide en dos partes para compararlo con los diferentes artículos que sirvieron como sus fuentes (13 y 18). 
De acuerdo con la primera porción del Artículo 19, la interpretación se debería enfocar en el significado de la letra de la ley ("el tenor literal"). La segunda parte del mismo artículo establece que el recurrir a la intención o al espíritu de la ley se permitirá solamente si alguna expresión de la ley es "obscura". Existía una clara coincidencia entre las reglas del Código Civil chileno y aquellas contenidas en los Artículos 13 y 18 del Código Civil de Luisiana. Los demás artículos del Código Civil chileno proporcionan reglas detalladas de cómo se debe interpretar la letra de la ley, y al hacerlo, también siguió el lenguaje del Código de Luisiana: se debería preferir el significado común de las palabras, salvo que se hayan empleado en un sentido técnico. Asimismo, el contexto (incluyendo la ley dentro de la cual se contenían las palabras y otras leyes que versan sobre materias similares) deberían ser tomados en cuenta.

Todas estas reglas estaban preocupadas de una interpretación literal: qué significado se le debería asignar a palabras aisladas (común, técnico o jurídico), y cuáles aspectos del contexto se deberían tomar en consideración (las disposiciones incluidas en la misma ley, y aquellas contenidas en leyes que versan sobre materias similares). Las reglas chilenas exhiben una marcada preferencia por el método literal de interpretación. La exploración de la intención del legislador o de la razón (o espíritu) de la ley, era una prioridad secundaria. La supremacía del método literal era acompañada por una serie de reglas detalladas dirigidas hacia una restricción adicional sobre el juez. Salvo por algunas diferencias, las cuales se detallarán a continuación, el Código Civil chileno siguió al Código de Luisiana.

Es entendible que el redactor del Código Civil chileno tomara inspiración del Código de Luisiana, ya que estaba convencido de que el método literal era la solución más adecuada para asuntos de interpretación de la ley. En 1842, Bello escribió lo siguiente:

Nosotros creemos que lo más seguro es atenerse a la letra; que no debemos ampliarla ni restringirla, sino cuando de ello resultan evidentes absurdos o contradicciones, ${ }^{132}$ y que todo otro sistema de interpretación abre anchas puertas a la arbitrariedad, y destruye el imperio de la ley. ${ }^{133}$

Según Bello, el método literal era un medio para evitar la "arbitrariedad", algo que se contraponía al estado de derecho ("imperio de la ley"). Quizás con algo de ironía, Bello se refirió a los antagonistas del método literal como aquellos que creían que "al internarse uno en la mente del legislador era el aspecto más sublime de la hermenéutica legal". ${ }^{134}$ En 1836, Bello, escribiendo mucho antes de la promul-

132 La expresión "salvo cuando se deriven de ello absurdos evidentes y contradicciones" era claramente similar a la regla dorada de Inglaterra (ver sección 2.2). Hay que destacar que, tal como en el derecho inglés, Bello restringe la regla de oro a los casos de absurdos y contradicciones (es decir, problemas lógicos), pero no lo aplica cuando el juez estima que una interpretación literal conduciría a resultados no-razonables o injustos.

133 BeLLo (1981), pp. 41-2.

134 Andrés Bello en El Araucano (Santiago de Chile, 30 Septiembre 1842), citado en BeLlo (1981), pp. 41-2: "mientras unos adhieren estrictamente al texto y tratan de licenciosa la inteligencia de 
gación del Código Civil, expresó una evidente desconfianza en contra del poder judicial, y escribió que el juez debería ser un "esclavo de la ley". ${ }^{135}$ Es más, así como Blackstone y otros redactores del Código de Luisiana, Bello creía que el référé au legislatif representaba una "gran inconveniencia", dado que "las leyes se degenerarían a ser (...) decisiones judiciales". ${ }^{136}$

Después de la entrada en vigencia del Código chileno, los juristas chilenos entendían que sus reglas de interpretación de la ley eran un respaldo al método literal. Los profesores de derecho que enseñaban en los años de 1850 en la Universidad de Chile (Enrique Cood y José Clemente Fabres) compartían esta misma opinión, la cual fue apoyada más adelante por su sucesor, Paulino. ${ }^{137}$ Mientras que Guzmán Brito ha sostenido acertadamente de que la opinión de aquellos profesores se basaba en una sobre-simplificación de la tradición del derecho civil. ${ }^{138}$ El mismo autor sostiene que el Código Civil chileno se había apartado efectivamente de dicha tradición. ${ }^{139}$ Este distanciamiento no fue solo el resultado de la influencia indirecta de Blackstone, sino que también reflejaba una convicción esencial de Bello. Es más, al contemplar las opiniones de Bello en cuanto a esta materia, debemos tener en mente que él era (y sigue siendo) uno de los gramáticos más destacados del idioma español, y probablemente, por tanto, el actor más sofisticado que abordara esta materia de entre aquellos que hemos analizado en el presente artículo. En su libro Gramática de la lengua castellana destinada al uso de los americanos, publicado por primera vez en 1847, Bello sostuvo que:

La utilidad de la gramática no puede ser más que inmenso, sea para hablar de una forma en la que se entienda lo que decimos (...) o para establecer precisamente el sentido de lo que han dicho otros; lo cual incluye nada menos que la enunciación correcta y la interpretación genuina de las leyes, contratos, testamento (....). ${ }^{140}$

Este párrafo ilustra la preferencia de Bello del enfoque gramatical, un enfoque que fue descrito por él como aquella que permite una interpretación "genuina" de las leyes. Sin perjuicio de que, desde el punto de vista interno de la teoría de la interpretación podamos aceptar o no la existencia de un método genuino de interpretación, este pasaje claramente demuestra la opinión del autor del Código Civil chileno, y lo que estaba intentado hacer con sus ideas al respecto. Así como se ha sostenido

sus antagonistas, otros creen que lo sublime de la hermenéutica legal es internarse en la mente del legislador [...] Por este medio, según conciben, se toman por guía, no las palabras de la ley sino su intención, su idea".

135 Bello, citado por Squella (1982), p. 72.

136 Bello (1954), p. 35.

137 GuZMán Brito (1992), pp. 41 y siguientes.

138 GuZmán Brito (1992), pp. 41 y siguientes.

139 Guzmán Brito (1992), p. 81.

140 BeLlo (1847), p. 1. Énfasis agregado por el autor. 
acertadamente, para Bello, la claridad y la unidad en el lenguaje y en el derecho constituían un objetivo político. ${ }^{141}$

\subsection{Diferencias entre los Códigos Giviles de Ghile y de Luisiana}

Tal como él mismo lo reconoció, Bello fue inspirado por el Código de Luisiana, pero él introdujo tres diferencias:

\section{(a) Definiciones legales de las palabras}

Primero, el Código Civil chileno establecía que, si una palabra había sido definida en una ley con un significado distinto a su acepción común y técnica, entonces debería seguir la definición jurídica. ${ }^{142}$ En sus apuntes, Bello admitía que había "introducido limitaciones" a los artículos del Código de Luisiana que versan sobre el sentido de las palabras comunes y técnicas, ${ }^{143}$ y explicó que "una palabra, sea o no técnica, no podría ser utilizada inapropiadamente en una ley", y preguntó retóricamente si "sería razonable asignarle a esa palabra un significado distinto a aquel asignado por el legislador". ${ }^{144}$ Esta limitación no se encontraba presente en el Código Civil de Luisiana.

\section{(b) Contexto no como una herramienta subsidiaria}

La segunda diferencia se refiere al uso del contexto para fines interpretativos. Mientras que el Código de Luisiana ${ }^{145}$ establecía (al igual que Blackstone y el derecho inglés), que el contexto de las palabras se debería consultar solamente cuando el significado de las palabras fuese ambiguo, bajo el Código Civil chileno ${ }^{146}$ las palabras se debieran siempre interpretar en su contexto, aun cuando fuese claro su significado.

\section{(c) Historia legislativa}

Tercero, y finalmente, recurrir a la intención de la legislatura o al espíritu de la ley, era permitido por el Código chileno solamente en casos de obscuridad. Esto era idéntico al Código Civil de Luisiana, y a Blackstone. Sin embargo, Bello agrego una disposición adicional: la intención de la legislatura se debía inferir solamente de fuentes fidedignas. La intención debería estar "claramente manifestada en la ley misma, o en la historia fidedigna de su establecimiento" (por ejemplo, discusiones parlamentarias). ${ }^{147}$ En su comentario sobre dicho artículo, Bello agregó que "las intenciones imaginarias no se deberían atribuir" a la legislatura. ${ }^{148}$ Esto marcó una divergencia

\footnotetext{
141 Hilbink (2007), p. 50.

142 Art. 20 y 21 del Código Civil Chileno.

143 Art. 14 y 15 del Código Civil de Luisiana.

144 BeLlo (1954), pp. 42-43.

145 Art. 16 Código Civil de Luisiana

146 Art. 22 Código Civil Chileno.

147 Art. 19 del Código Civil Chileno, inciso 2.

148 Bello (1954), p. 43.
} 
del derecho inglés en el cual recurrir a los procedimientos legislativos (Hansard) se había resistido desde $1760 .{ }^{149}$ Recién en 1993, la House of Lords permitió recurrir a Hansard, y, aun así, la decisión se encontró con un intenso debate. Uno de los argumentos más tradicionales en contra del acudir a la historia legislativa, era la dificultad de reconstruir dicho proceso, una dificultad que podría ser superada cuando el Informe Hansard asumiera su forma moderna en el siglo veinte. Bello tenía preocupaciones similares cuando insistía que la intención debería ser "clara", derivada de fuentes "fidedignas", y no fuentes "imaginarias". Sin embargo, contrario al derecho inglés, el Código chileno permitía la consideración de la historia legislativa para fines interpretativos.

\subsection{Inspiración para las disimilitudes}

Las diferencias entre el Código Civil chileno y el Código Civil de Luisiana no eran cruciales en el sentido de que la idea central de restringir la discreción judicial se reflejaba de forma similar en ambos Códigos. Sin embargo, dichas variaciones merecen exploración, ya que muestran algo de divergencia del literalismo estricto del derecho inglés. En el Código chileno, el uso del contexto para la interpretación, aun cuando las palabras estén claras, y la legitimidad al recurso a los procedimientos legislativos, hacen que el textualismo sea más flexible que el estricto literalismo ${ }^{150}$ inglés. Más aún, las exploraciones de estas diferencias darán mayor luz a la inspiración angloamericana en esta área: las ideas de James Kent.

En las siguientes secciones, rastrearé en primer lugar la influencia de Kent. Para este propósito, necesitamos recurrir al Código Civil de Uruguay, promulgado en 1868, en relación con el cual dicha inspiración fue explícitamente reconocida por Tristán Narvaja, el redactor del Código. Finalmente, en las conclusiones regresaré a la distinción entre estas dos variedades del literalismo: el literalismo estricto inglés y la versión sudamericana más flexible de la misma.

\subsection{El Código Givil de Uruguay y la Influencia de Kent}

\subsubsection{Tomar prestado del Código Givil chileno}

Los artículos 17 al 20 del Código Civil del Uruguay reproduce las reglas del Código chileno sobre la interpretación de la ley, con tan solo una leve (e irrelevante) omisión. ${ }^{151}$ El redactor de la versión final del Código Civil uruguayo, Tristán Narvaja, reconoció la influencia del Código chileno, una inspiración que también fue evidenciada por el lenguaje idéntico de las disposiciones correspondientes.

149 Para este párrafo: Vogenauer (2005), pp. 629-74.

150 Sección 2.2. anterior.

151 Leyes sobre in pari materia no se mencionaron. 
Al igual que Bello, Narvaja mantenía fuertes puntos de vista sobre la materia de interpretación de la ley. ${ }^{152}$ Primero, vinculó el método literal de interpretación con la estabilidad. En este respecto, en una de sus obras, citó favorablemente a un político francés (Vaublanc), dirigiéndose a la Asamblea Nacional en 1792: "Establecer (...) el despotismo del derecho, o temer el desarrollo de todas las causas de desorden que Francia oculta en su seno”. En segundo lugar, Narvaja fue explícitamente crítico de la postura adoptada por el Código Civil francés (1804), el cual, tal como se mencionó anteriormente, ${ }^{153}$ no incluía reglas sobre la interpretación de la ley. Narvaja sostenía que:

Puede ocurrir en algunas instancias que la ley (...) debido a la imperfección del lenguaje, pueda ser obscura (...) El Código Uruguayo, que anticipaba el problema, y que ha sido más explícito en esta parte que el francés (...) ha tenido el deseo de proporcionarle al juez, en esta embarazosa situación, la consignación (...) de reglas hermenéuticas. ${ }^{154}$

Narvaja consideraba que la inclusión de reglas que gobernaran la interpretación de la ley, era para "imponer sobre todos, la obligación de obedecerlas", con el fin de prevenir que dichas reglas fuesen meras "tesis filosóficas", como lo eran en Francia. ${ }^{155}$ Así, tal como Bello se apartó de la tradición civilista, Narvaja se apartó del Código Civil francés. Esta información será relevante cuando le encontremos el sentido a las influencias angloamericanas sobre la interpretación de la ley.

\subsubsection{Kent utilizado por Narvaja}

Uno de los aspectos interesantes de tomar prestadas las reglas de interpretación de la ley de Chile por parte de Uruguay, fueron los comentarios de Narvaja. Los artículos 18 al 20 del Código uruguayo fueron una transcripción literal de los artículos 20 al 22 del Código chileno. Tal como se ha mencionado, dichos artículos chilenos fueron inspirados por las correspondientes reglas del Código de Luisiana, pero existían algunas diferencias entre ellas. Entre dichas diferencias, se encuentra la alusión a la definición legal de las palabras, y la disposición sobre la consideración del contexto, aún para la interpretación de palabras claras (es decir, no como una herramienta subsidiaria). Narvaja mencionó explícitamente a Kent en relación a estas dos disposiciones.

\section{(a) Definiciones legales}

Tal como se ha mencionado, los Códigos chilenos y uruguayos disponen que la definición legal de una palabra debe prevalecer por sobre su significado común o

152 Para todas las referencias contenidas en este párrafo: NARVAJA (2008), pp. 360-1.

153 Sección 3.5 anterior.

154 Narvaja (2008), pp. 360-1

155 Narvaja (2008), pp. 360-1. 
técnico, ${ }^{156}$ una idea que no estaba presente en el Código de Luisiana. En sus apuntes sobre los artículos correspondientes del Código uruguayo (18 y 19), Narvaja citó el siguiente párrafo de Kent:

Si fuesen utilizadas palabras técnicas, deben ser tomadas en su contexto técnico, salvo que aparezca claramente del contexto, o de otras partes del instrumento, de que la intención era que las palabras se aplicaran de forma distinta a la de su acepción común o legal. Comentarios de Kent. ${ }^{157}$

La última parte de la oración de Kent citada por Narvaja, fue casi idéntica con la adición introducida por Bello en el artículo 21 del Código chileno, y tomado por Narvaja en el artículo 19 del Código uruguayo. La expresión en inglés de Kent "unless it clearly appears" fue traducida palabra por palabra al español de la siguiente manera: "a menos que aparezca claramente". En la tabla que se encuentra a continuación, se comparan el párrafo de Kent con los artículos correspondientes de Uruguay y de Chile, con las similitudes destacadas en negritas:

\begin{tabular}{|c|c|c|}
\hline Comentarios de Kent ${ }^{158}$ & Código Civil Chileno & Código Civil de Uruguay \\
\hline \multirow{2}{*}{$\begin{array}{l}\text { Si se utilizan palabras } \\
\text { técnicas, deben ser to- } \\
\text { madas en un sentido } \\
\text { técnico, salvo que apa- } \\
\text { rezca claramente del } \\
\text { contexto, o de otras par- } \\
\text { tes del instrumento, de } \\
\text { que la intención era que } \\
\text { las palabras se aplicaran } \\
\text { de forma distinta a la } \\
\text { de su acepción común } \\
\text { o legal. }\end{array}$} & $\begin{array}{l}\text { Art. 20. Las palabras de la ley } \\
\text { se entenderán en su sentido } \\
\text { natural y obvio, según el uso } \\
\text { general de las mismas palabras; } \\
\text { pero cuando el legislador } \\
\text { las haya definido expresa- } \\
\text { mente para ciertas mate- } \\
\text { rias, se les dará en éstas su } \\
\text { significado legal. }\end{array}$ & $\begin{array}{l}\text { 18. Las palabras de la ley se } \\
\text { entenderán en su sentido na- } \\
\text { tural y obvio, según el uso ge- } \\
\text { neral de las mismas palabras; } \\
\text { pero cuando el legislador } \\
\text { las haya definido expresa- } \\
\text { mente para ciertas mate- } \\
\text { rias, se les dará en éstas su } \\
\text { significado legal. }\end{array}$ \\
\hline & $\begin{array}{l}\text { Art. 21. Las palabras técnicas } \\
\text { de toda ciencia o arte se toma- } \\
\text { rán en el sentido que les den los } \\
\text { que profesan la misma ciencia } \\
\text { o arte; a menos que aparez- } \\
\text { ca claramente que se han } \\
\text { tomado en sentido diverso. }\end{array}$ & $\begin{array}{l}\text { Art. 19. Las palabras técni- } \\
\text { cas de toda ciencia o arte se } \\
\text { tomarán en el sentido que les } \\
\text { den los que profesan la misma } \\
\text { ciencia o arte; a menos que } \\
\text { aparezca claramente que } \\
\text { se han tomado en sentido } \\
\text { diverso. }\end{array}$ \\
\hline
\end{tabular}

156 Art. 20 y 21 del Código Civil Chileno, y los art. Idénticos 18 y 19 del Código Civil de Uruguay.

157 Narvaja (1910), p. 5. "Aceptación legal" en Kent, se debe entender como "significado técnico".

$158 \operatorname{Kent}(1851)$, p. 511. 
Así, adicionalmente a la mención explícita de Narvaja de Kent, se dio una clara similitud de redacción entre los Códigos Civiles uruguayos y chilenos, y el párrafo de Kent, tal como indicó correctamente Narvaja, fue tomado de Parte III, Discurso XX, de los Comentarios sobre el Derecho Americano de Kent. Así, la idea de que las definiciones legales deberían prevalecer sobre el significado común y técnico de las palabras, fue asociado por Narvaja con las ideas de Kent, y es muy posible que Kent haya sido la fuente de inspiración para Bello, así como se explicará a continuación.

\section{b) Contexto como algo más que una herramienta subsidiaria}

El redactor del Código Civil uruguayo también aludió a los Comentarios de Kent, en relación con el artículo 20 del Código uruguayo. Dicho artículo fue una transcripción literal del Artículo 22 del Código Civil chileno. Tal como se mencionó anteriormente, ${ }^{159}$ a diferencia del Código de Luisiana, el artículo del Código chileno estableció que el uso del contexto para los fines de interpretación no estaba sujeto a las palabras con significado ambiguo. Referente a esta regla en particular, en sus apuntes, Narvaja se refiere a Kent Parte III Discurso XX, ${ }^{160}$ pero no mencionó un párrafo específico. Sin embargo, no es difícil encontrar referencias a la obra de Kent sobre la idea de que el uso del contexto no estaba sujeto a la existencia de dudas sobre el significado de las palabras. Por ejemplo, en el mismo párrafo mencionado anteriormente, Kent indica que aun cuando el significado común o técnico de una palabra fuese claro "el contexto, u otras partes del mismo instrumento" podrían indicar que se debería aplicar un significado distinto. ${ }^{61}$ Similarmente, en otro párrafo, Kent sugiere que la "intención del legislador debe ser deducida de la totalidad y de cada parte de una ley, tomada y comparada juntamente". ${ }^{162}$ Sin embargo, esta idea no se le atribuye solamente a Kent. En sus comentarios, Narvaja también citó la Ley 24, Título 3, Libro 1 del Código de Justiniano, y el artículo VI del Proyecto Francés (1800), el cual establecía lo mismo. Así, se puede ver el uso de contexto aun cuando eran claras las palabras, como una característica del enfoque del derecho civil, la cual fue retenida por los Códigos chilenos y uruguayos, y que fue adoptada por Kent, más que una influencia angloamericana significativa. Esto marcó la diferencia del literalismo estricto del derecho inglés, el cual permitía hasta la década de 1950, tal como se ha mencionado, la consulta del contexto en caso de un lenguaje ambiguo. ${ }^{163}$

\section{c) Procedimientos legislativos}

Narvaja no hizo mención de Kent en cuanto al uso de la historia legislativa. Sin embargo, se debe notar que Kent era mucho más abierto al uso de la historia legislativa que el derecho inglés. Kent, al igual que Bello, estaba al tanto de las dificultades

\footnotetext{
159 Sección 4.2. anterior.

160 Narvaja (1910), p. 5.

161 Kent (1854), p. 511.

162 Kent (1854), p. 511.

163 Ver Sección 2.2 anterior.
} 
de reconstruir la intención legislativa, ${ }^{164}$ pero no descartaba la posibilidad. Así, Kent escribió que, en caso de duda, el preámbulo de una ley podría "ayudar a remover las ambigüedades cuando la intención no sea llana". ${ }^{165}$

A modo de resumen, no es sorprendente que la influencia de Kent contribuyó al relajamiento del estricto literalismo inglés en los Estados Unidos, y de forma indirecta en Sudamérica. Desde el inicio de su análisis del derecho positivo, es claro que el enfoque de Kent no era el mismo del derecho inglés. Por ejemplo, a diferencia de Blackstone, Kent estipuló que el juez no podría aplicar una ley que contradijera la Constitución, y que la intención de la legislatura debería prevalecer por sobre el significado literal, cuando dicha intención se pudiera determinar de manera clara ${ }^{166}$. Así, Kent no apoyaba un modelo jerárquico, ni apoyaba la deferencia radical por el derecho creado por el Parlamento que caracterizaba el enfoque inglés. En cierto sentido, la concepción chilena de interpretación de la ley ocupaba una posición entre el derecho inglés y Kent. Era más flexible que el literalismo estricto del derecho inglés, pero más estricto que las ideas de Kent.

\subsection{3. ¿Por qué se refirió Narvaja a Kent?}

Andrés Bello, redactor del Código chileno, estaba muy familiarizado con las obras de Kent. ${ }^{167}$ Sin embargo, no mencionó que Kent se encontraba entre sus fuentes de inspiración para la interpretación de la ley. Entonces, ¿por qué Narvaja en Uruguay se refirió a Kent? Existen dos posibles explicaciones. Primero, Narvaja descubrió por él mismo que existía una coincidencia interesante entre las reglas del Código chileno y las obras de Kent, pero Narvaja no sospechaba que Bello las había utilizado en esta área. Segundo, él tenía acceso a la evidencia que indicaba que no era simplemente una coincidencia fortuita, sino que Bello había sido inspirado por las ideas de Kent, y Narvaja simplemente lo reconoció. En mi opinión, la segunda es la interpretación más probable, aunque existen argumentos para ambas explicaciones.

En cuanto a la primera hipótesis, (esto es, que Narvaja mismo descubrió la coincidencia con Kent en este campo), existen dos consideraciones que apoyan este punto de vista. El primero, y el más obvio, es el silencio de Bello respecto de Kent. El segundo no es tan evidente: el pasaje que Narvaja cita de Kent, ${ }^{168}$ no estaba presente en las primeras tres ediciones de los Comentarios de Kent. Apareció por primera vez en la cuarta edición de 1840. Esto le habría dado a Bello tiempo suficiente para saber de ello antes de comenzar la redacción de sus reglas de interpretación de la

164 KeNT (1851), p. 509. El título y el preámbulo de una ley "no son generalmente expositores seguros de la ley".

165 Kent (1851), p. 509.

166 Kent (1851), p. 510.

167 Referencias hechas a James Kent se encuentran, por ejemplo, en Bello (1885); Bello (1954); Bello (1955); BeLLO (1832).

168 Ver Sección 4.4.2. (a) anterior. 
ley por primera vez en 1853.169 Sin embargo, esta interpretación es problemática debido a que, en relación a otro tema en su borrador de 1853 del Código chileno, Bello se refirió a la segunda edición de los Comentarios de Kent, ${ }^{170}$ edición en la cual no existía el pasaje citado por Narvaja. Esto tiende a apoyar la teoría que Narvaja, y no Bello, consultó los escritos de Kent sobre esta materia. Sin embargo, esta opción dejaría sin explicación las coincidencias anteriormente señaladas sobre la redacción entre Kent y Bello.

Por otro lado, existen varios factores que apoyan la segunda explicación posible (esto es, en vez de acertar una coincidencia que él encontró, Narvaja estaba indicando que Bello había sido inspirado por Kent). Bello estaba bastante interesado y familiarizado con las obras de Kent, las cuales consultó respecto de diversas áreas (incluyendo la sucesión intestada, derecho internacional, etc.). Es perfectamente posible que él haya tenido acceso y consultara ediciones posteriores de las obras de Kent, las que estaban circulando fácilmente en Sudamérica, sin citarlas como tales. Luego surge una segunda pregunta: si Bello utilizó la cuarta edición de Kent (o una edición posterior), y no lo mencionó públicamente en relación a la interpretación de la ley, ¿cómo podría saber Narvaja que Bello había sido inspirado por Kent? ¿Y por qué no lo reconoció Bello? Para la primera pregunta, existe una explicación simple: Narvaja vivió en Chile entre 1845 y 1853, durante el período en el que se estaban discutiendo los borradores sucesivos del Código Civil chileno, ${ }^{171}$ por lo que podría haber sabido del uso de Kent por parte de Bello en esta área. De hecho, el primo de Narvaja, Gabriel Ocampo, un abogado destacado que también vivía en Chile, era uno de los miembros de la comisión que, juntamente con Bello, revisaron la versión de 1853 del Código Civil chileno. Ya hemos visto que, durante los trabajos de la comisión, Ocampo tomó notas sobre la materia de interpretación de la ley, marcando una diferencia con las ideas de Domat. ${ }^{172}$ Esto demuestra un interés en el tema, y es probable que haya habido algo de debate sobre el mismo en la comisión. Es más, sabemos que Ocampo mantuvo contacto frecuente con Narvaja. ${ }^{173}$ Por lo tanto, es posible que Narvaja estuviese al tanto, por medio de Ocampo, del uso de Bello de las ideas de Kent, aunque Bello no lo reconociera públicamente. Todas estas son solamente posibilidades que hacen que la hipótesis sea plausible. Sin embargo, la evidencia clave en mi opinión es la coincidencia del lenguaje entre el pasaje de Kent citado por Narvaja, y el artículo 21 del Código chileno. La expresión "al menos de que aparezca claramente" en ambos textos, señala hacia la dirección de que Bello tomó prestado de Kent. En mi opinión, este último punto, tomado junto con el interés de Bello y de otros abogados chilenos respecto de las obras de Kent en esta

169 BeLlo (1955), p. 1066. En la versión de 1853, las reglas estaban enumeradas del 17 al 19.

170 La anotación de Bello del Art. 593 del Código Civil Chileno, sobre un aspecto del derecho internacional, se refiere de forma explícita a la segunda edición de Kent. Bello (1954), p. 417.

171 Para esta y las referencias siguientes sobre la estadía de Narvaja en Chile, ver: Peirano Facio (2008): pp. 35-36.

172 Ver Sección 3.2 anterior.

173 KLeinheisterkamp (2006), p. 7. 
época, hace que sea muy probable que Bello mismo fuese inspirado por Kent, y que Narvaja (quien estaba en una posición de saberlo), simplemente reconoció dicha influencia.

En cuanto al por qué Bello guardó silencio sobre el uso de las ideas de Kent, hay dos hipótesis: una hipótesis neutra y una política. La primera explicación puede ser que él consideraba que las ideas de Kent no eran tan relevantes como el uso que le dio Bello al Código de Luisiana, el cual proporcionó la matriz de reglas que influyó sobre el Código Civil chileno. Así, quizás Bello pensaba que la contribución menor de Kent no merecía ser mencionada en cuanto a esta materia. La segunda explicación podría ser que, sabiendo que las ideas de Kent sobre la interpretación de la ley difieren de su propio enfoque literalista, Bello no deseaba llamar la atención a él como una valiosa fuente de inspiración. Kent era un crítico de la deferencia de Blackstone y del derecho inglés respecto del derecho creado por el Parlamento, y favorecía una revisión judicial de las leyes por parte de los jueces, en casos en los que las leyes estaban en contravención con la Constitución. ${ }^{174}$ Este aspecto distintivo del pensamiento de Kent no habría sido aceptado por Bello, quien estaba mucho más interesado en hacer del juez un "esclavo de la ley", tal como hemos visto anteriormente. ${ }^{175}$

En resumen, es muy probable que Bello haya utilizado las obras de Kent con la finalidad de enmendar algunas de las reglas del Código de Luisiana de la interpretación de la ley. No reconoció dicho uso, ya sea por razones políticas o no-políticas, pero Narvaja divulgó la existencia de dicha inspiración.

Tomando todas las cosas en consideración, a pesar de que Kent no fuese la influencia principal, este episodio revela, según mi punto de vista, un interés abarcador general respecto de las ideas angloamericanas en el campo de la interpretación de la ley, y más probable aún, más que eso. Por lo menos, Narvaja estaba muy interesado en ellas. Esto en sí es revelador: una intranquilidad respecto de la solución francesa ${ }^{176}$ condujo a Narvaja, y probablemente a Bello, a consultar sobre las ideas angloamericanas del tema.

\subsection{Trasplante a Ecuador y Colombia}

Las ideas de Blackstone inspiraron el Código Civil de Luisiana, tal como se ha demostrado en las secciones previas. Del Código de Luisiana, dichas ideas viajaron al Código Civil chileno de 1855, y fueron complementadas por las ideas de Kent. En un paso final, las ideas de Blackstone viajaron a los Códigos Civiles del Ecuador (1858), Uruguay (1868) y Colombia (1887). Tal como se ha mencionado, las reglas chilenas sobre la interpretación de la ley fueron tomadas por el redactor del Código

174 KeNT (1854), pp. 493-4.

175 Ver Sección 4.1

176 Ver Sección 4.4.1. 
Civil uruguayo. ${ }^{177}$ En el caso de Ecuador y de Colombia, se dio un verdadero trasplante del Código Civil chileno como un todo. ${ }^{178}$

El artículo 18 del Código Civil ecuatoriano de 1858 fue una copia de las reglas de interpretación de la ley del Código Civil chileno: los cuatro párrafos del artículo 18 reprodujeron los artículos 19 al 22 de Chile. Lo mismo ocurrió con el Código Civil colombiano de 1887: sus artículos 27 al 31 reprodujeron las reglas del Código Civil chileno sobre la interpretación de la ley de forma literal.

Por lo tanto, en un proceso de tres pasos de influencia indirecta, Blackstone inspiró las reglas sobre interpretación de la ley del Compendio de Luisiana (1808), y del Código Civil de Luisiana (1825). El derecho de Luisiana inspiró el Código Civil chileno (1855), y subsiguientemente, las reglas chilenas fueron trasplantadas en Ecuador (1858), Uruguay (1868), y Colombia (1887). ${ }^{179}$ De esta forma, cuatro jurisdicciones en Sudamérica adoptaron en sus códigos civiles, una concepción de interpretación de la ley inspirada por Blackstone. Dicha concepción era muy similar al derecho inglés en cuanto al predominio que se le otorgó a la regla del significado llano, aunque se ablandó de alguna forma el estricto literalismo del derecho inglés, debido a las influencias del derecho civil y de Kent. ${ }^{180}$

\section{5. ¿TENÍA GONSGIENGIA BELLO DE LA INFLUENGIA DE BLAGKSTONE?}

Las preguntas que siguen sin responder son aquellas que determinan si Bello tenía consciencia de que Blackstone fue la fuente para las reglas sobre interpretación de la ley del Código Civil de Luisiana, y si la respuesta es afirmativa, por qué nunca lo reconoció.

No he encontrado indicación alguna de que Bello o Narvaja reconozcan explícitamente una relación entre el Código de Luisiana y Blackstone en este asunto. Es más, la conexión entre Blackstone y el Código de Luisiana sobre interpretación de la ley fue cerciorado por Rodolfo Batiza recién en los años 70, y aún en ese entonces, se miraba como algo "sorprendente" ${ }^{181}$ En Chile, hasta el 2004, la visión que se mantenía, era de que la fuente más probable de inspiración para las reglas de interpretación de la ley de los códigos de Luisiana y de Chile, fue Domat por medio del Proyecto Francés de $1800 .{ }^{182}$ Considerando todo lo anterior, sería razonable inferir que Bello ignoraba la conexión entre el Código de Luisiana y Blackstone. ¿Cómo

177 Ver Sección 4.4 anterior.

178 Mirow (2004), p. 137.

179 El Código Civil de Venezuela de 1862, un trasplante del Código Civil Chileno de 1855, también adoptó las reglas de interpretación de la ley de este último. Sin embargo, fue un código de corta vida, y cuando fue reemplazado por el Código Civil de 1867, dichas reglas sobre interpretación de la ley no fueron reproducidas.

180 Ver Sección 4.2 anterior.

181 Batiza (1971), p. 29.

182 GuZmán Brito (2004), p. 41. 
podría haber sabido algo que fue reconocido tan recientemente y de forma tan reticente? Sostengo que sería un error emitir un juicio retrospectivo en base a nuestra mentalidad contemporánea, ya que podemos estar condicionados relativamente por la visión tradicional de las fuentes de inspiración del derecho privado sudamericano.

El alcance de la lectura de los actores jurídicos angloamericanos en Sudamérica del siglo diecinueve es algo que ha sido subestimado muchas veces, por los historiadores del derecho contemporáneos. La percepción normal es que los juristas sudamericanos podrían haber tenido uno o dos volúmenes de Bentham, Blackstone o Kent en sus repisas, pero que nada tomaron concreto o relevante de la lectura de dichos volúmenes. Sin embargo, en Sudamérica hubo un patrón consistente de lectura y aplicación de ideas jurídicas angloamericanas para fines académicos y legislativos. Los juristas sudamericanos del siglo diecinueve estaban más familiarizados que sus sucesores con el derecho angloamericano. Hemos ignorado, o bien subestimado, dicha familiaridad de manera consistente. Tomando todo lo anterior en consideración, debemos ajustar nuestro lente con tal de evaluar si Bello o sus contemporáneos sudamericanos podrían haber sabido de la relación entre Blackstone y el Código de Luisiana en esta área.

Por ejemplo, es notable que Bello haya vivido en Inglaterra por veinte años, donde pasó parte de su tiempo estudiando el derecho inglés. Él estaba familiarizado con las obras de Blackstone, las cuales él citó en relación a otros temas y, así como hemos visto, lo más probable es que Bello haya consultado a Kent en materia de interpretación de la ley. Se debe notar además que Kent referenció a Blackstone desde el inicio de su capítulo sobre la interpretación de la ley. La intención de las menciones de Kent sobre Blackstone era destacar una disimilitud clave entre el enfoque inglés y americano de la interpretación de la ley: Blackstone fue presentado por Kent como el defensor del principio inglés de deferencia por el derecho creado por el Parlamento. Aún si Bello no hubiese consultado a Blackstone directamente respecto de este tema, la alusión de Kent lo habría conducido al autor inglés. Además, al leer a Bentham, un autor con el que Bello estaba bien familiarizado, también podría haberlo alertado. Bentham elogió a Blackstone como uno de los juristas más respetuosos hacia la autoridad del Parlamento. Es más, en la opinión de Bentham, Blackstone tenía el honor de ser segundo después de Bentham mismo. Dado el interés de Bello en asegurar que el juez fuese un "esclavo de la ley", ${ }^{183}$ todo lo anterior no habría caído en oídos sordos.

Bello era dueño de un ejemplar de Commentaries on the Lawes of England de Blackstone, cosa que sabemos por el inventario de su biblioteca, ${ }^{184}$ e hizo uso de él muchas veces. ${ }^{185}$ Tomando en consideración todos estos factores, razonablemente podemos

183 Ver Sección 4.1 anterior.

184 Un catálogo de manuscritos de la biblioteca de Bello está bajo custodia de la Universidad de Chile: biblio.uchile.cl/client/search/asset/92351, visitado el 8 de febrero del 2015.

185 Por ejemplo, hay referencias a Blackstone en los apuntes de Bello del Código Civil Chileno, y su libro Principios de Derecho de Jentes, publicado en 1832. 
aceptar por lo menos una de las dos siguientes conclusiones: Bello estaba al tanto de la similitud del lenguaje y de la sustancia entre Blackstone y el Código de Luisiana, o por lo menos, él se dio cuenta que las concepciones de interpretación de la ley en Blackstone y en el Código de Luisiana eran muy similares, estableciendo, tal como lo hicieron, el predominio de la regla literal, encarnando una desconfianza hacia la discreción del juez.

Si Bello estaba consciente del pedigrí 'Blackstoneano' de las reglas del Código de Luisiana sobre la interpretación de la ley, entonces ¿por qué no lo mencionó? Me parece que la explicación es la misma explicación estratégica que hemos encontrado en otras instancias de los 'préstamos legales'. En Chile, por ejemplo, el debate que se suscitó por medio de la prensa chilena entre Andrés Bello y Miguel María Güemes durante 1840 sobre el derecho sucesorio intestado, ${ }^{186}$ reveló que algunos actores jurídicos, tales como Güemes, tenían una preferencia por fuentes del derecho civil. Las fuentes de inspiración angloamericanas aparecieron en la escena cuando el derecho civil no pudo apoyar las reformas sugeridas por los redactores de la legislación, y requerían algunas credenciales para lo mismo, tal como sucedió, para otro campo, cuando Bello intentó mejorar la situación del cónyuge sobreviviente. ${ }^{187}$ En ese contexto, el Código de Luisiana siempre fue una mejor credencial que Blackstone. No se podía poner en duda su suficiencia liberal, y su origen de derecho civil proporcionaba un escudo para los ataques por parte de practicantes de mentalidad estrecha. Al desestimar el derecho inglés o estadounidense como fuentes encomiables de inspiración, Güemes excluyó solo al derecho de Luisiana de sus ataques. ${ }^{188}$

A mi juicio, es altamente probable que Bello estuviese consciente del origen Blackstoneano del material que él estaba utilizando. Y así como estaba al tanto de ello, estratégicamente hablando, era mejor mencionar el Código Civil de Luisiana, en vez de Blackstone. Ocurrió una situación similar con respecto al uso de Bello sobre las reglas referentes a las corporaciones o las personas jurídicas del Código Civil de Luisiana. Fueron claramente influenciados por Blackstone, pero nunca fue reconocido por Bello. ${ }^{189}$

Finalmente, aunque la influencia de Blackstone no fuese consciente, sí existió. Una idea puede influenciar aún a aquellos que no están al tanto de su origen. El camino hacia atrás desde el Código Civil chileno a Blackstone es claro. Es más, la similitud entre las ideas de Blackstone y el literalismo inglés, nos muestra que a fin de cuentas existe una influencia indirecta del derecho inglés sobre el Código chileno (y sus secuelas), en lo que se refiere a la interpretación de la ley.

186 BeLLo (1885), pp. 304-400.

187 BeLLo (1885), pp. 304-400.

188 Miguel María Güemes: su artículo sin título está incluido en BeLLo (1885), pp. 362-366.

189 KNÜtel (1995-1996), pp. 1458-9. 


\section{CONGLUSIONES}

\subsection{De Blackstone a Ghile, Ecuador, Uruguay y Colombia}

Las secciones previas de este artículo versaron sobre la influencia de Blackstone en materia de interpretación de la ley en cuatro códigos sudamericanos. Mostraron que, al principio, las reglas de interpretación de la ley del Código Civil de Luisiana (1825) fueron claramente inspiradas por Blackstone. El lenguaje de los artículos 14 al 18 del Código de Luisiana fue claramente tomado de Blackstone, junto con el enfoque general respecto de la interpretación judicial representado en dicho código.

En segundo lugar, había cierta "originalidad" en las ideas de Blackstone que las apartaron de la tradición civilista. Así, su obra no fue solamente una adaptación de las ideas del derecho civil tomadas de Pufendorf. Blackstone desarrolló la idea central que caracterizaba el enfoque inglés hacia la interpretación de la ley en el siglo diecinueve: el literalismo estricto.

Tercero, el Código Civil chileno (1855) fue inspirado por el Código Civil de Luisiana en materia de interpretación de la ley, tal como fue reconocido por su redactor, Andrés Bello. Así, el Código Civil chileno fue influenciado indirectamente por Blackstone y por el derecho inglés.

Cuarto, una serie de modificaciones al modelo de Luisiana introducido por Bello fue, probablemente, inspirada por los Comentarios de Kent, lo cual resultó en la adopción por el Código Civil chileno de un enfoque relativamente flexible del literalismo, cuando lo comparamos con aquel enfoque utilizado en el derecho inglés, estando relacionadas las diferencias principales con el uso interpretativo del contexto y la historia legislativa.

Finalmente, las reglas sobre la interpretación de la ley del Código Civil chileno (1855) viajaron a otros tres Códigos Civiles de Sudamérica: Ecuador (1858), Uruguay (1868) y Colombia (1887), donde fueron adoptadas sin modificación relevante alguna.

\subsection{Disposiciones republicanas y modelos insatisfactorios de derecho civil}

Los cuatro códigos civiles sudamericanos anteriormente señalados adoptaron un modelo legal formalista de interpretación de la ley, ${ }^{190}$ la que denominaré como Literalismo Sudamericano. Dicho modelo, así como el enfoque desarrollado por Blackstone y por el derecho inglés, priorizaba una regla literal o de significado llano, en virtud de la cual un juez podría tomar en consideración la intención de la legislatura o la razón (espíritu) de la ley, solamente si persistiera alguna duda después de la aplicación de la regla literal.

Este enfoque de la interpretación de la ley se diferencia de aquel enfoque de la tradición representada por Domat y Pufendorf, quienes son considerados como las

190 Así como el Código de corta vida, el Código Civil de Venezuela de 1862. 
fuentes más relevantes de inspiración en esta área, para cuando fueron promulgados los Códigos Civiles de Luisiana y de Chile. En términos simples, dichos autores no sostenían un modelo jerárquico que le diera prioridad a la regla literal. En cambio, en su opinión, el juez podía desestimar la clara letra de la ley, si es que darle efecto a dicho significado fuese contrario al "bien común" o a la "ley natural", o si la intención legislativa fuese distinta del significado literal de la ley. En cuanto a la intención de la legislatura, dichos autores representaban lo que se mira incluso hoy como la postura que caracteriza al derecho civil en esta materia: el predominio de la intención de la legislatura por sobre la letra de la ley. ${ }^{191}$ Algunos contemporáneos chilenos, como Gabriel Ocampo, estaban al tanto de que el modelo adoptado por el Código Civil chileno implicaba una desviación de los escritos de Domat. ${ }^{192}$ Es más, el literalismo sudamericano se puede diferenciar también del derecho español, el cual seguía el método del référé au legislatif. ${ }^{193}$ Finalmente, si consideramos otros códigos de la tradición del derecho civil, se puede ver nuevamente lo especial de los Códigos de Luisiana y de Chile. Por ejemplo, el artículo 6 del Código Civil de Austria de 1811, y el artículo 4 del Código Civil de Cerdeña de 1837, ${ }^{194}$ no adoptaron un modelo jerárquico. Dichos códigos establecían que el "significado de las palabras: y la "intención de la legislatura" se debían considerar simultáneamente. Por lo tanto, el literalismo sudamericano tenía coincidencias con Blackstone y con el derecho inglés, pero se difería de la tradición del derecho civil, con la sola excepción del Proyecto Francés (1800), el cual veremos a continuación.

El único modelo de derecho civil que podría proporcionar inspiración para esta rama americana del literalismo era el Proyecto Francés (1800), del cual uno de los artículos, tal como vimos, ${ }^{195}$ inspiró el artículo 13 del Código Civil de Luisiana. Esta versión sin éxito le otorgaba prioridad a la regla literal, y contenía reglas detalladas de interpretación, aunque eran bastante distintas a aquellas contenidas en el Código Civil de Luisiana. Sin embargo, el Proyecto fue descartado en poco tiempo. En su lugar, el Código Civil francés (1804) no regulaba la interpretación judicial en lo absoluto, y poco tiempo después, en 1807, el derecho francés reintrodujo el mecanismo del référé au legislatif. La solución francesa no se miraba de forma positiva en Luisiana y en Sudamérica. Narvaja, redactor del Código Civil uruguayo, fue explícitamente crítico respecto de la ausencia de reglas sobre interpretación de la ley en el Código francés. ${ }^{196} \mathrm{El}$ référé au legislatif no era considerado como una posibilidad viable, por una variedad de razones. En primer lugar, para cuando había progresado la codificación en Sudamérica, ya había fallado en términos prácticos el référé francés, y fue abandonado en 1837. En segundo lugar, al igual que Blackstone, tanto los redactores de los códigos de Chile como de Luisiana, expresaron opiniones ne-

191 Freeman (2008), p. 1555.

192 Ver Sección 3.2. anterior.

193 Sección 3.3. anterior.

194 Mencionado por Narvaja en sus apuntes al Código Civil del Uruguay, ver Narvaja (2008), p. 5.

195 Sección 3.5. anterior.

196 Sección 4.4.1. anterior. 
gativas sobre la idea de que la legislatura asumiera el rol de intérprete de la ley para casos judiciales concretos. Así como la discreción judicial podría convertir al poder judicial en una legislatura, el référé au legislatif podía convertir a la legislatura en un juez. El référé era considerado como una seria vulneración del principio de separación de poderes como discreción judicial.

Guando se toman en consideración todos los factores analizados en los párrafos previos, una explicación por fin surge, sobre los eventos que llevaron a esta "sorprendente" convergencia con el derecho inglés. Las legislaturas sudamericanas necesitaban adaptar el antiguo derecho español a "nuevas disposiciones políticas republicanas". ${ }^{197}$ Dichas disposiciones obviamente incluían un compromiso con el principio de separación de poderes, sobre el cual existía un amplio consenso: el liberalismo era el "discurso político dominante en América Latina". ${ }^{198}$ El Código Civil francés era el modelo de preferencia. Sin embargo, a falta de una solución francesa aceptable, los redactores legislativos sudamericanos miraron a otros países, Inglaterra y los Estados Unidos, los cuales eran vistos como instituciones liberales. ${ }^{199}$

\subsection{Literalismo inglés y sudamericano}

La influencia de Blackstone y del derecho inglés sobre la interpretación de la ley en Chile no fue una simple imitación pasiva, sino que el resultado de una empresa reflexiva, donde fue críticamente evaluado el modelo original, y adaptado de forma creativa a la realidad sudamericana. La solución divisada por Bello tomó su inspiración de diversas fuentes. No siguió "servilmente" los enfoques civiles o de derecho inglés. En la sección previa he enfatizado las diferencias entre el literalismo sudamericano y las tradiciones de derecho civil. Ahora, debemos observar sus diferencias con el literalismo inglés estricto. De hecho, este artículo mostró la influencia del modelo inglés, pero también mostró algunas de las diferencias. Existían dos diferencias principales: ${ }^{200}$ en Sudamérica, el contexto de las palabras fue presentado como un elemento primario de interpretación, y el uso de la historia legislativa se permitía para fines interpretativos.

En cuanto al uso del contexto, la explicación de la divergencia puede ser técnica. Bello fue un actor legal, pero tal como hemos dicho, también fue un importante gramático. Él habría entendido que el Código de Luisiana y Blackstone lo llevaron demasiado lejos. Tal como sugiere Endicott, "cada técnica sensata de interpretación jurídica incluye una versión del principio de contexto" ${ }^{201}$ Es una característica general de los idiomas, no solo de los textos legales, que las "variaciones de los con-

197 JAKSIC (2001), p. 174.

198 Rivera (2016), pp. 1 y 10.

199 Bello, "Publicidad de los Juicios", en Bello (1885), p. 6.

200 La tercera diferencia con el Código de Luisiana (esto es, la referencia a las definiciones legales en el Código chileno inspiradas por Kent), pareciera ser meramente técnica, y no tan importante para los fines de ver un contraste entre los dos modelos aquí considerados.

201 EndicotT (2002), pp. 949-50. 
textos hacen que sea apropiado extender la aplicación de una palabra en diversas formas". ${ }^{202}$ Mi propuesta es que Bello, con una percepción más sofisticada de la lingüística, se dio cuenta que, si el juez desacataba el principio de contexto, habría sido capaz de "estropear las palabras utilizadas en la legislación". ${ }^{203}$ En otras palabras, Bello percibía que el significado de las palabras no se podría establecer si se tomaban fuera de su contexto. Esta percepción, junto con la tradición de derecho civil, y la opinión de Kent, de siempre considerar el contexto, ${ }^{204}$ pueden explicar esta diferencia entre las dos versiones de literalismo.

Con respecto a la segunda diferencia (el uso de la historia legislativa), el literalismo sudamericano asumió una postura muy similar al enfoque norteamericano. ${ }^{205}$ El Código chileno y sus secuelas establecieron dos reglas sobre el uso de la historia legislativa. En primer lugar, el juez podría investigar la intención del legislador solamente si el texto de la ley no fuese claro. En segundo lugar, consultas sobre la intención legislativa deberían enfocarse en la ley misma, o en fuentes "fidedignas". Tal como dijo Bello, los jueces no deberían inventar intenciones "imaginarias". Estas reglas se pueden ver desde dos perspectivas cuando se comparan. En primer lugar, con el Código Civil de Luisiana y Blackstone, y segundo, con el derecho inglés a lo largo de su desarrollo durante el siglo diecinueve.

Si comparamos las disposiciones de Chile con las del Código de Luisiana o con Blackstone, se puede ver que el Código chileno es más rígido y formalista. Mientras que el Código de Luisiana y Blackstone permitían la investigación de la intención de la legislatura en caso de dudas, no limitaban las fuentes que se podrían usar para elucidar dicha intención. Pareciera que Bello estaba al tanto del problema que no consideraban Blackstone y el Código de Luisiana. Siempre ha existido una discusión en el derecho angloamericano sobre las dificultes de reconstruir la historia legislativa. ${ }^{206}$ Kent, por ejemplo, se refirió a este obstáculo pragmático. El requisito de usar fuentes "fidedignas" en el Código chileno, se basó en esta consideración problemática. Así, este requisito hace que el Código chileno sea mucho más formalista que sus fuentes (Código de Luisiana y Blackstone). ${ }^{207}$

Sin embargo, cuando comparamos el Código chileno con el derecho inglés respecto al uso de la historia legislativa, pareciera que el Código chileno es más flexible. El derecho inglés rechazaba el uso de la historia legislativa, aun cuando se estableció Hansard de manera firme como un informe oficial y "fidedigno" al inicio del siglo

202 Endicott (2002), pp. 949-50.

203 EndicotT (2002), pp. 949-50.

204 Por ejemplo, Domat y Art. VI del Projet Francés (1800).

205 WaLdron (1999), p. 119.

206 Millar v. Taylor (1769), p. 2332 (Willes J).

207 Uno podría sostener que el requisito del Código chileno es una mera redundancia. En otras palabras: ¿qué juez postularía cierta intención del legislador, y luego sostendría que su conclusión se basa en fuentes no-fidedignas? Sin embargo, una vez más, no estoy analizando la coherencia lógica interna del requisito, sino que la preocupación práctica que se revela para los actores históricos. 
veinte. Recién en los años 90, la House of Lords permitió la consulta sobre la historia legislativa. ${ }^{208}$ ¿Qué les impedía a los jueces ingleses consultar la historia legislativa? Debía ser un motivo más que las meras dificultades prácticas. Debería existir una razón basada en principio. Lord Steyn recientemente sugirió que estaba en juego el principio de separación de poderes. En atención a las relaciones entre el gobierno y el Parlamento en el Reino Unido, las declaraciones sobre la intención legislativa eran en verdad "declaraciones de ministros" hechas en el Parlamento, por lo que existe la preocupación de que la consideración de la historia legislativa podría resultar en un vuelco del poder de creación de la ley del Parlamento al poder ejecutivo. ${ }^{209}$ Dichas reservas no se aplican a Norte y Sudamérica, debido a las estructuras distintas de la relación entre el gobierno y el Parlamento, o una falta de preocupación con esta clase de interferencia por parte del ejecutivo respecto del significado de las leyes.

A diferencia de Inglaterra, para algunos sudamericanos del siglo diecinueve, no parecía ser problemática la admisión de declaraciones de ministros como consideración relevante para la interpretación de la ley. En verdad, sugiero que podrían haberse considerado. El ideal liberal de separación de poderes, ampliamente aceptado en Sudamérica, puede explicar el interés de restringir la discreción judicial, al igual que el rechazo del référé au legislatif. También puede explicar por qué los redactores sudamericanos de legislación miraron a Luisiana y a las ideas jurídicas angloamericanas como fuentes de inspiración, en ausencia de una solución francesa aceptable. Sin embargo, el contexto sudamericano en el que se implementaron estas ideas, podría explicar la diferencia con el derecho inglés en materia de relevancia de historia legislativa. Veremos esto a continuación.

\section{4. ¿Buscando separación de poderes u orden y seguridad?}

Después de la independencia, la vasta mayoría de políticos e intelectuales sudamericanos compartían una misma base liberal, ${ }^{210}$ y estaban de acuerdo en cuanto a un gobierno republicano y separación de poderes. Sin embargo, a mediados del siglo diecinueve, empezaron a surgir diferencias entre quienes eran llamados Liberales y Conservadores, en base a una terminología sudamericana específica. Ambos compartían un principio común, pero tenían diferencias en cuanto a grados: los conservadores preferían una regla más fuerte y centralizada. ${ }^{211} \mathrm{Su}$ objetivo principal era el de recuperar el orden después de un período caótico de post-independencia.

Algunos historiadores sudamericanos han interpretado los intentos de Bello de subyugar a los jueces (hacer que fuesen "esclavos de la ley") ${ }^{212}$ como no parte de

208 Pepperv. Hart (1993).

209 Lord Steyn (2001), p. 70. Este mismo argumento se presenta en Black-Clawson International Ltd. V. Papierwerke Waldhof-Aschaffenburg AG (1975), AC 591 at 629 (Lord Wilberforce), citado por Vogenauer (2005), pp. 632 y 647.

210 Buschnell y Macaulay (1994), p. 12, Rivera (2016), p. 10.

211 Rivera (2016), p. 10.

212 Souella (1982), p. 72. 
una agenda liberal, sino que una expresión de su convicción conservadora sobre la necesidad de una autoridad centralizada. La adopción de Bello del literalismo interpretativo se ha conectado explícitamente con su preocupación por "asegurar orden y estabilidad en Chile", en lugar de ideas de "Pensadores de la Ilustración". ${ }^{213}$ Se ha planteado que su temor más grande no era que los jueces subvencionarían la voluntad popular, sino que destruirían la autoridad del estado. ${ }^{214}$

Lo mismo se podría decir de Narvaja en Uruguay. Usando los términos peculiares de Sudamérica de su época, él no era Liberal, ${ }^{215}$ aun cuando compartía la base liberal que se sostenía comúnmente en su época. El Código Civil uruguayo fue promulgado por un dictador (General Venancio Flores), aunque fue ratificado más adelante por el Parlamento, y las preocupaciones de Narvaja y de sus contemporáneos se enfocaban principalmente en establecer orden y progreso económico en Uruguay en términos económicos liberales. ${ }^{216}$ En Uruguay, durante la segunda mitad del siglo diecinueve, el vuelco hacia un control centralizado "dominaba la narrativa sobre la reforma legal". ${ }^{217}$ Los líderes políticos con capacitación legal buscaban reformas del sistema legal como parte de una solución para las políticas disruptivas de los caudillos (líderes de milicia no-oficiales) ${ }^{218}$. Por lo tanto, también en Uruguay, la subyugación de jueces se podría mirar como parte de un intento general de consolidar la autoridad central del estado, así como parte de un esfuerzo liberal por implementar separación de poderes.

Lo más probable es que la idea de limitación a la discreción de los jueces se había inspirado realmente por ambas preocupaciones: asegurar el orden y la implementación de disposiciones republicanas.

Además, es interesante notar que esta materia importante fue abordada en los Códigos Civiles y no en las Constituciones de las nuevas repúblicas sudamericanas. Esto puede ser en sí una indicación de que la preocupación principal era el proporcionar orden y seguridad a nivel económico. Este argumento es clásico: si desea atraer actores a un nuevo mercado, primero debe proporcionar reglas claras. En un artículo de prensa publicado en 1869, los redactores del Código Civil uruguayo expresaron la idea que "el Código regula las libertades civiles (...) para atraer la población, el capital y las industrias que hacen falta en nuestro país". ${ }^{219}$ En Chile, Andrés Bello y otros actores jurídicos estaban convencidos de que, si se podía asegurar la certidumbre en la interpretación de reglas jurídicas, seguiría el crecimiento

213 Hilbink (2007), p. 49.

214 Hilbink (2007), p. 49.

215 Oddone-Blanca Paris (2010), p. 129.

216 Chasteen (2011), p. 194. Esta era una característica común de todos los liberales económicos desde 1870 en adelante en Sudamérica. La implementación de una economía liberal se hacía normalmente a través de los gobiernos autoritarios.

217 Benton (2001), p. 507.

218 Benton (2001), p. 507.

219 Narvaja, “La Nación tiene Código Civil”, en Peirano Facio (2008), p. 251. 
económico. ${ }^{220}$ Desde aquella perspectiva, el literalismo sudamericano era parte de la empresa de lograr el orden y la estabilidad por el bien del desarrollo económico. La estabilidad se debía lograr no solo mediante la codificación, sino también al desalentar la distorsión judicial de los Códigos por medio de su interpretación.

En otras palabras, si adoptamos un enfoque contextualista ${ }^{221}$ sobre lo que estaban haciendo los actores sudamericanos con la idea de literalismo, encontramos que, en el contexto del siglo diecinueve, no podía ser el objetivo el subyugar un poder judicial que ya era poderoso (a diferencia de Francia revolucionaria, por ejemplo), ya que el poder judicial no podría ser poderoso en lo absoluto. El problema enfrentado por los sudamericanos era la falta de autoridad de los nuevos estados que aparecieron después de la independencia. La separación de poderes dentro de los gobiernos era quizás, el debate aparente. Sin embargo, probablemente, el crear un marco apropiado para la imposición de autoridad gubernamental era el objetivo real.

220 Hilbink (2007), p. 45.

221 Sección 1 anterior. 


\section{BIBLIOGRAFÍA CITADA}

BatizA, Rodolfo (1971). "The Louisiana Civil Code of 1808: Its Actual Sources and Present Relevance”, Tulane Law Review, Vol. 46, pp. 4-165.

Barham, Mack E. (1975-1976). "Methodology of the Civil Law in Louisiana" (19751976), Tulane Law Review, Vol. 50, pp. 476-494.

Bascuñán Rodríguez, Antonio (2014). "El mito de Domat”, en Grez, Pablo et. al. (coords.), Una vida en la Universidad de Chile: Celebrando al Profesor Antonio Bascuñán Valdés (Legal Publishing), pp. 263-349.

Bello, Andrés (1832). Principios de Derecho de Jentes (Imprenta de la Opinión).

Bello, Andrés (1847). Gramática de la Lengua Castellana para el Uso de los Americanos (Imprenta del Progreso).

Bello, Andrés (1885). Obras Completas de don Andrés Bello: Volumen IX: Opúsculos Jurídicos (Imprenta Pedro G. Ramírez).

Bello Andrés (1954). Obras Completas: Tomo XII: Código Civil de la República de Chile, Volumen I (Ministerio de Educación).

Bello, Andrés (1955). Obras Completas: Tomo XIII: Código Civil de la República de Chile: Volumen II (Ministerio de Educación).

Bello, Andrés (1981). Código Civil de la República de Chile: Volumen I: Introducción y notas de Pedro Lira Urquieta, Profesor de la Universidad de Chile y de la Católica de Santiago: Texto concordado con los distintos Proyectos de Bello (Obras Completas, Volumen XIV, 2nd ed., Fundación La Casa de Bello).

Benton, Lauren (2001). "The laws of this Country: Foreigners and the Legal Construction of Sovereignty in Uruguay: 1830-1875", Law and History Review Vol. 19, pp. 479-511.

BIx, Brian (2015). Jurisprudence: Theory and Context (7th. edn. Sweet \& Maxwell).

Blackstone, William (1783). Commentaries of the Laws of England: Vol.1 (9th ed., W Strahan, T Cadell and D Prince).

Bushnell, David and Macaulay, Neil (1994). The Emergence of Latin America in the Nineteenth Century (2nd edn., Oxford University Press).

CAIRns, John W. (2009). “The De la Vergne Volume and the Digest of 1808”, Tulane European \& Civil Law Forum, Vol. 24, pp. 31-81.

Chasteen, John Charles (2011). Born in Blood \& Fire: A Concise History of Latin 
America (WW Norton \& Co.).

Dawson, John P. (1968). The Oracles of Law (University of Michigan Law School).

Domat, Jean (1689). Les Loix Civiles dans Leur Ordre Naturel (Chez Jean Baptiste Coignard).

Domat, Jean (1737). The Civil Law in its Natural Order Together with the Publick Law: Volume I (William Strahan translator, 2nd ed.).

Dworkin, Ronald (1998). Law's Empire (Hart Publishing).

EndicotT, Timothy (2002). "Law and Language", en Coleman, Jules and Shapiro, Scott (eds.), The Oxford Handbook of Jurisprudence and Philosophy of Law (Oxford University Press).

Frank, Jerome (1949). Law and the Modern Mind (Stevens).

FrankLIN, Mitchell (1940-1941). "Libraries of Edward Livingston and Moreau Lislet”, Tulane Law Review, Vol. 15, pp. 401-414.

Franklin, Mitchell (1941-1942). "Place of Thomas Jefferson in the Expulsion of Spanish Medieval Law from Louisiana", Tulane Law Review, Vol. 16, pp. 319338.

Freeman, Michael D.A. (2008). Lloyd's Introduction to Jurisprudence (8th ed., Sweet \& Maxwell).

Ghestin, Jacques and Gobeaux, Gilles (1994). Traité de Droit Civil: Introduction Générale (4th ed., LGDJ).

Greenawalt, Kent (2002). "Constitutional and Statutory Interpretation", en Coleman, Jules and Shapiro, Scott (eds.), The Oxford Handbook of Jurisprudence and Philosophy of Law (Oxford University Press).

Guzmán Brito, Alejandro (1992). "La Historia Dogmática de las normas sobre interpretación recibidas por el Código Civil de Chile", en Universidad de Chile-Universidad Adolfo Ibañez, Interpretación, Integración y Razonamiento Jurídicos (Editorial Jurídica de Chile).

GuZmán BRito, Alejandro (2004). "La Doctrina de Jean Domat sobre la Interpretación de las Leyes", Revista Chilena de Derecho, Vol. 31, pp. 39-68.

GuZMÁn Brito, Alejandro (2009). "Las fuentes de las normas sobre interpretación de las leyes del 'digeste des lois civiles' ('Code civil') de la Luisiana (1808/1825)”, Revista de Estudios Histórico-Jurídicos, Vol. 31, pp. 171-195.

Guzmán Brito, Alejandro (2011). Codificación del Derecho Civil e Interpretación de las Leyes (Iustel).

Harris, James W. (2007). Legal Philosophies (2nd edn., Oxford University Press).

Hart, H.L.A. (1956). "Blackstone's Use of the Law of Nature", Butterworths South African Law Review, pp. 169-174. 
Herman, Shael (2008). "The Louisiana Code of Practice (1825): A Civilian Essay Among Anglo-American Sources". Electronic Journal of Comparative Law, Vol 12.1, available at http://www.ejcl.org.

Hilbink, Lisa (2007). Judges Beyond Politics in Democracy and Dictatorship: Lessons from Chile (Cambridge University Press).

JAKsic, Iván (2001). Andrés Bello, Scholarship and Nation-Building in 19th Century Latin America (Cambridge University Press).

Jones, Gareth (ed.) (1973). The Sovereignty of the Law: Selections from Blackstone's Commentaries on the Laws of England (Palgrave Macmillan).

Kent, James (1851). Commentaries on American Law: Vol. 1 (7th. ed., William Kent).

Kent, James (1854). Commentaries on American Law: Volume I (8th ed., William Kent).

Kleinheisterkamp Jan (2006). "Development of Comparative Law in Latin America", en Reimann Mathias and Zimmerman Reinhard (eds.), The Oxford Handbook of Comparative Law (Oxford University Press).

KnÜtel, Rolf(1995-1996). "Influences of the Louisiana Civil Code in Latin America”, Tulane Law Review, Vol. 70, pp. 1445-1480.

Livingston, Edward et. al. (1823). To the Honorable Senate and House of Representatives of the State of Louisiana (JC de St Romes State Printer).

Lobban, Michael (2004). "Introduction: The Tools and the Tasks of the Legal Historian", en Lewis, Andrew and Lobban, Michael (eds.), Law and History: Current Legal Issues 2003 Volume 6 (Oxford University Press).

Lord Steyn (2001). "Pepper v Hart: A Re-examination”, Oxford Journal of Legal Studies, Vol. 21, pp. 59-72.

López, Gregorio (ed.) (1555). Las Siete Partidas del Sabio Rey Don Alonso el Nono nuevamente glosadas por el Licenciado Gregorio López del Consejo Real de Indias de su Majestad: Tomo I (Salamanca).

López Medina, Diego (2012). "The Latin American and Caribbean Legal Traditions", en Bussani, Mauro and Mattei, Ugo (eds.), The Cambridge Companion to Comparative Law (Cambridge University Press).

LÜcke, Horst Klaus (2005). "Statutory Interpretation: New Comparative Dimensions. Book review of Interpretation of Statutes in England and on the Continent. A Comparative Study of Judicial Jurisprudence and Its Historical Foundations by Stefan Vogenauer", The International and Comparative Law Quarterly, Vol. 54, No. 4, pp. 1023-1032.

Manning, John F. (2001). "Textualism and the Equity of the Statute" (2001) Columbia Law Review, Vol. 101, pp. 1-127. 
Mirow, Matthew C. (2004), Latin American Law: A History of Private Law and Institutions in Spanish America (University of Texas Press).

Moreau Lislet, Louis (1968). A reprint of Moreau Lislet's Copy of A Digest of the Civil Laws now in Force in the Territory of Orleans: 1808: Containing Manuscript References to its Sources and Other Civil Laws on the Same Subjects: The de la Vergne Volume (Louisiana State University School of Law and Tulane University School of Law).

Narvaja, Tristán (1910). Fuentes, Notas y Concordancias del Código Civil de la República Oriental del Uruguay (Tipografía y Litografía Oriental).

Narvaja, Tristán (2008). "De la sociedad conyugal y las Dotes", en Peirano Facio, Jorge, Tristán Narvaja. Un Jurista Rioplatense en tiempos de la Codificación (Instituto de Investigaciones de Historia del Derecho).

Oddone-Blanca Paris, Juan (2010). Historia de la Universidad de la República: Tomo I (2nd ed., Ediciones Universitarias).

PARISE, Agustin (2012). "Codification of the Law in Louisiana: Early Nineteenth-Century Oscillation between Continental European and Common Law Systems", Tulane European \& Civil Law Forum, Vol. 27, pp. 133-164.

Peirano Facio, Jorge (2008). Tristán Narvaja. Un Jurista Rioplatense en tiempos de la Codificación (Instituto de Investigaciones de Historia del Derecho).

Planiol, Marcel and Ripert, Georges (1997). Derecho Civil: Parte A: Volumen 3 (Ed. Harla México).

Plucknett, Theodore F.T. (2010). A Concise History of the Common Law (Liberty Fund).

Pufendorf, Samuel (1717). Of the Law of Nature and Nations: Book 5 (translated by William Percivale).

RiverA, Faviola (2016). "Liberalism in Latin America", en Zalta, Edward (ed.), The Stanford Encyclopedia of Philosophy (Spring 2016 ed. https://plato.stanford.edu/ archives/spr2016/entries/liberalism-latin-america/).

Rorty, Richard (1979). Philosophy and the Mirror of Nature (Princeton University Press).

Skinner, Quentin (1978). The Foundations of Modern Political Thought. Volume One: The Renaissance (Cambridge University Press).

SQuella, Agustín (1982). "Proyección Jurídica de las Ideas de Bello sobre el Orden y la Libertad", in Departamento de Ciencias del Derecho: Facultad de Derecho: Universidad de Chile, Congreso Internacional Andrés Bello y el Derecho (Editorial Jurídica de Chile).

Tucker, Thomas (1969-1970). "Sources of the Louisiana Law of Persons: Blackstone, Domat and the French Codes", Tulane Law Review, Vol. 44, pp. 264-295.

van Caenegem, Raoul C. (1992). An Historical Introduction to Private Law (Cambridge University Press). 
Vogenauer, Stefan (2005). "A Retreat from Pepper v Hart? A Reply to Lord Steyn", Oxford Journal of Legal Studies, Vol. 25, pp. 629-674.

WALDRON, Jeremy (1999). Law and Disagreement (Oxford University Press).

Watson, Alan (1978). "Comparative Law and Legal Change", Cambridge Law Journal, Vol. 37, pp. 313-336.

WeinRib, Ernest J. (2012). The Idea of Private Law (revised ed., Oxford University Press). 


\section{JURISPRUDENGIA CITADA}

\section{Inglaterra y Nueva Gales:}

Fulmerston v Steward (1554), Plowd. 109.

Dr.Bonham's Case, 8 Co. Rep. 114 (Court of Common Pleas [1610]).

Millar v Taylor (1769) 1 Burr 2303 (KB).

Sussex Peerage Case (1844) 11 Gl \& Fin 85.

Attorney-General v Prince Ernest Augustus of Hanover [1957] AC 436.

Pepper v Hart [1993] A.C. 593. 